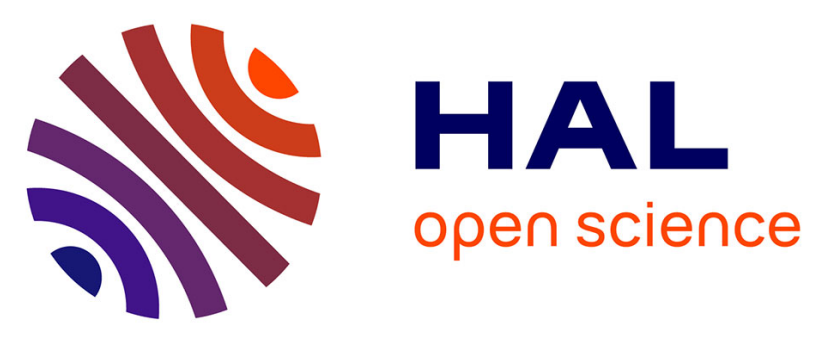

\title{
Linkage Photoisomerization Mechanism in a Photochromic Ruthenium Nitrosyl Complex: New Insights from an MS-CASPT2 Study
}

Francesco Talotta, Jean-Louis Heully, Fabienne Alary, Isabelle M. Dixon, Leticia González, Martial Boggio-Pasqua

\section{To cite this version:}

Francesco Talotta, Jean-Louis Heully, Fabienne Alary, Isabelle M. Dixon, Leticia González, et al.. Linkage Photoisomerization Mechanism in a Photochromic Ruthenium Nitrosyl Complex: New Insights from an MS-CASPT2 Study. Journal of Chemical Theory and Computation, 2017, 13 (12), pp.6120-6130. 10.1021/acs.jctc.7b00982 . hal-01684087

\section{HAL Id: hal-01684087 \\ https://hal.science/hal-01684087}

Submitted on 19 Dec 2018

HAL is a multi-disciplinary open access archive for the deposit and dissemination of scientific research documents, whether they are published or not. The documents may come from teaching and research institutions in France or abroad, or from public or private research centers.
L'archive ouverte pluridisciplinaire HAL, est destinée au dépôt et à la diffusion de documents scientifiques de niveau recherche, publiés ou non, émanant des établissements d'enseignement et de recherche français ou étrangers, des laboratoires publics ou privés. 


\title{
Linkage Photoisomerization Mechanism in a
}

\section{Photochromic Ruthenium Nitrosyl Complex:}

\section{New Insights from an MS-CASPT2 Study}

Francesco Talotta, ${ }^{\star}$ Jean-Louis Heully, Fabienne Alary, ${ }^{\prime}$ Isabelle M. Dixon, Leticia González, ${ }^{*}$

Martial Boggio-Pasqua *

Laboratoire de Chimie et Physique Quantiques, UMR 5626, IRSAMC, CNRS et Université

Toulouse 3, 118 route de Narbonne, 31062 Toulouse, France.

${ }^{\sharp}$ Institut für Theoretische Chemie, Fakultät für Chemie, Universität Wien, Währinger Str. 17, 1090 Vienna, Austria.

\begin{abstract}
The $\mathrm{N} \rightarrow \mathrm{O}$ linkage photoisomerization mechanism in a ruthenium nitrosyl complex, $\left[\mathrm{RuCl}(\mathrm{NO})(\mathrm{py})_{4}\right]^{\text {ta }}$, for which a quasi complete photoconversion between the stable nitrosyl (N-bonded) and metastable isonitrosyl (O-bonded) isomers has been observed under continuous irradiation of the crystal at $473 \mathrm{~nm}$ (Cormary et al., Acta Cryst. B 2009, 65, 612623), is investigated using multiconfigurational second-order perturbation theory (CASPT2). The results support efficient intersystem crossing pathways from the initially excited singlet states to the lowest triplet excited state of metal-to-ligand charge transfer character ( ${ }^{3} \mathrm{MLCT}$ ). The topology of the involved potential energy surfaces corroborates a complex sequential two-photon
\end{abstract}


photoisomerization mechanism involving nonadiabatic processes in agreement with experimental observations and previous density functional theory calculations.

\section{INTRODUCTION}

The design of original photochromic compounds has been the center of intense research in photochemistry in order to build innovative functional materials for information processing and storage ${ }^{1,234.5}$ photocontrol in biological systems ${ }^{6,7}$ and photomechanical actuators ${ }^{8.9}$ The vast majority of reported photochromic compounds relies on organic molecules often undergoing photoinduced electrocyclic reactions..$^{1-3,10,1,12}$ However, transition metal complexes have also been designed to display photochromic properties. These systems are based on linkage isomerizations between the metal center and ambidentate ligands. ${ }^{13,14,1,5,6,1,1,18}$ Among these systems, ruthenium nitrosyl complexes have attracted growing interest over the past two decades, not only owing to their photochromic properties but also because of their capability to photorelease nitric

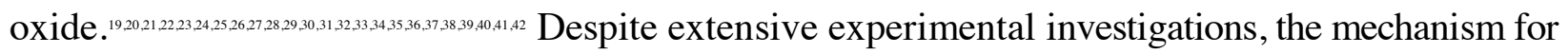
these two competing processes remained unclear until recently.$^{43}$

Computational studies investigating the linkage photoisomerization mechanisms of metal complexes remain relatively scarce owing to the difficulty to compute the excited-state potential energy landscape in such systems.4+ The most significant contributions are based on density functional theory (DFT) calculations of the $\mathrm{S} \rightarrow \mathrm{O}$ linkage photoisomerization pathways in ruthenium and osmium sulfoxide complexes ${ }^{4546477,48,49}$ and of the $\mathrm{P} \rightarrow \mathrm{O}$ linkage photoisomerization pathway in a phosphinidene oxide ruthenium complex. ${ }^{18}$ Very recently, the $\mathrm{N} \rightarrow \mathrm{O}$ linkage 
photoisomerization pathway in the $\left[\mathrm{RuCl}(\mathrm{NO})(\mathrm{py})_{4}\right]^{]^{+}}$(where py denotes pyridine ligands) ruthenium nitrosyl complex, was investigated using a similar DFT-based strategy. ${ }^{.0}$ This study shed some light on the mechanistic picture of the $\mathrm{N} \rightarrow \mathrm{O}$ linkage photoisomerization. In contrast to ruthenium sulfoxide and phosphinidene oxide complexes for which energetically favorable linkage photoisomerization pathways on the lowest triplet excited state were characterized ${ }^{1 \text { sastaf }}$ the triplet excited-state pathway for the $\mathrm{N} \rightarrow \mathrm{O}$ linkage photoisomerization reveals an activated and energetically uphill process..$^{50}$ On account of these results, a complex sequential two-photon photoisomerization mechanism involving nonadiabatic processes was proposed $^{50}$ and later confirmed experimentally." As illustrated in Figure 1, the most stable N-bonded ground-state isomer (denoted GS) absorbs a blue light photon, which brings the system in excited singlet metal-to-ligand charge transfer ('MLCT) states. These states are assumed to quickly relax by intersystem crossing (ISC) due to significant spin-orbit coupling (SOC) and by internal conversion (IC) to the lowest triplet MLCT excited state ( ${ }^{3}$ MLCT) leading to the N-bonded triplet state ${ }^{3} \mathbf{G S}$. The system then encounters a large barrier $($ ca. $1 \mathrm{eV})$ on the adiabatic triplet potential energy surface (PES) to reach the NO-bonded ${ }^{3}$ MS2 intermediate. A more accessible route is provided by ISC at a triplet/singlet crossing point allowing the system to decay at the MS2 singlet state. A key feature of this mechanism is that this metastable state can also absorb the same blue light photon as GS, as revealed by the computed electronic absorption spectra with time-dependent DFT (TD-DFT). ${ }^{50}$ The system can then be re-excited to 'MLCT states from which non-radiative decays by ISC and IC lead to the population of ${ }^{3}$ MS2. From this intermediate, a small adiabatic barrier needs to be overcome to reach the O-bonded ${ }^{3}$ MS1. Another singlet/triplet crossing lying nearby allows for ISC to the O-bonded MS1 product. This final photoproduct does not absorb in the blue light spectral range. Thus, this proposed mechanistic picture accounts 
for the change of color of a single crystal of trans-[RuCl(NO)(py) $)_{4}\left(\mathrm{PF}_{6}\right)_{2} \cdot 1 / 2 \mathrm{H}_{2} \mathrm{O}$ from orange (GS) to green (MS1) with a very high photoconversion yield observed upon irradiation in the 473-476 nm region. ${ }^{3535638}$ This sequential two-photon absorption mechanism was recently confirmed by visible absorption spectroscopy."

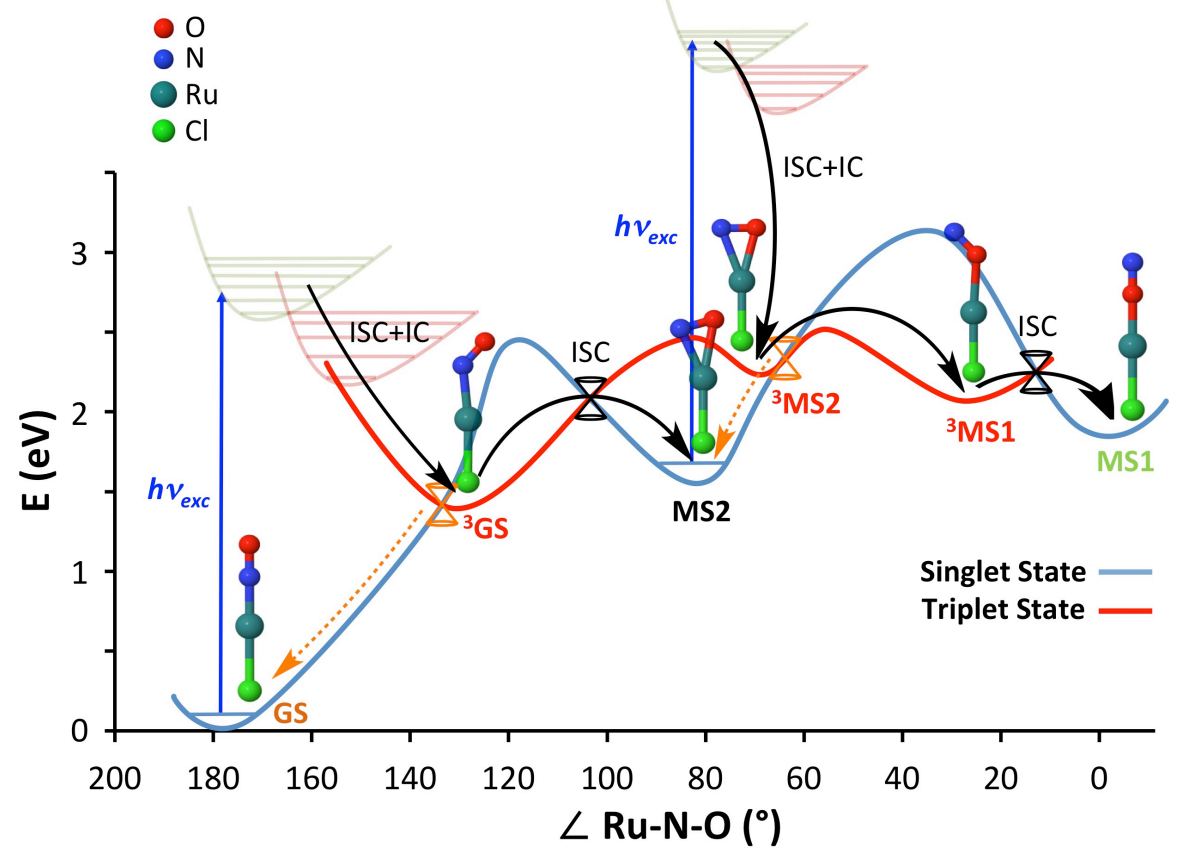

Figure 1. Potential energy profiles for the singlet ground state (blue curve) and the lowest triplet state (red curve) along the $\mathrm{N} \rightarrow \mathrm{O}$ linkage photoisomerization pathway derived from DFT calculations in Ref. [50]. The reaction coordinate is represented as the Ru-N-O angle. GS, MS2 and MS1 correspond to the N-bonded, NO-bonded and O-bonded isomers in the singlet state, respectively. ${ }^{3} \mathbf{G S}$, ${ }^{3} \mathbf{M S 2}$ and ${ }^{3} \mathbf{M S 1}$ correspond to the N-bonded, NO-bonded and O-bonded isomers in the triplet state, respectively. Pyridine ligands have been omitted for clarity. ISC and IC stand for intersystem crossing and internal conversion. Double-cone pictograms represent the minimum energy crossing points between the singlet and triplet states (in black the two ones relevant to $\mathrm{N} \rightarrow \mathrm{O}$ linkage photoisomerization). The black arrows indicate the sequential steps of 
the $\mathrm{N} \rightarrow \mathrm{O}$ linkage photoisomerization mechanism. The orange dashed arrows and orange double cones represent photostabilizing non-radiative decay paths to GS and MS2.

However, this DFT-based study relies on the assumption that the photochemical properties of the studied complex can be rationalized based on the population of the lowest triplet excited state. While it is reasonable to think that the lowest excited state will eventually be populated, relaxation pathways from the initially excited singlet states and their possible deactivation to higher triplet states by ISC have not been considered thoroughly. In other words, the initial part of the photochemical path has largely been overlooked and assumed to lead to the lowest excited state on an ultrafast timescale. The ground for such an assumption relies on previous reports of

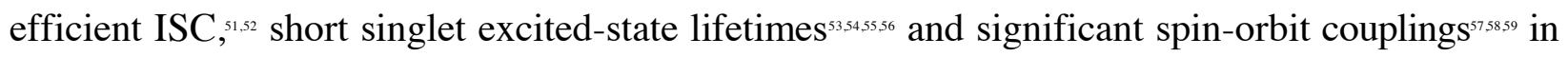
polypyridine ruthenium complexes, and SOC dynamics simulations in a ruthenium nitrosyl complex showing highly efficient ultrafast decay to the lowest triplet state.$^{60}$ In addition, this study relied on single-reference DFT to compute complex excited-state energy landscape including regions of bond breaking and bond formation where multiconfigurational character in the electronic state wavefunction is expected. ${ }^{61}$ Thus, it is important to benchmark DFT results against more reliable multiconfigurational wavefunction-based methods. ${ }^{62}$

The purpose of the present work is to investigate with an accurate ab initio method the photoisomerization pathways for the $\left[\mathrm{RuCl}(\mathrm{NO})(\mathrm{py})_{4}\right]^{2_{+}}$complex based on a static picture provided by the computation of the potential energy landscapes of relevant electronic states along the reaction paths. To achieve this goal, multiconfigurational methods based on complete active space self-consistent field (CASSCF) and multistate complete active space second-order perturbation theory (MS-CASPT2) calculations including SOC have been performed to study the 
initial ISC pathways and to revisit the photoisomerization mechanism, in comparison to the previous DFT results.

\section{COMPUTATIONAL DETAILS}

Multiconfigurational ab initio calculations were performed using the CASSCF and MSCASPT2 methods. ${ }^{63}$ These calculations have three main objectives: (i) determine the electronic structures and vertical transition energies associated with the low-lying excited states of the three isomers GS, MS2 and MS1, (ii) investigate the main ISC pathways after initial irradiation of GS, and (iii) determine the potential energy landscape along the photoisomerization reaction paths. All reference CASSCF calculations were performed distributing 16 electrons in 13 molecular orbitals. This active space, shown in Figure 2 for the GS isomer, was chosen in view of the photoisomerization process, which mainly involves the three atoms $\mathrm{Ru}, \mathrm{N}$, and $\mathrm{O}$, with a $\mathrm{Ru}-\mathrm{N}$ bond breaking and a $\mathrm{Ru}-\mathrm{O}$ bond formation. Accordingly, the five $\mathrm{Ru}(4 \mathrm{~d})$ valence orbitals need to be included, together with the orbitals directly interacting with them, in particular along the Ru-N-O axis. The active orbitals thus include the five $4 \mathrm{~d}$ valence orbitals, the two pairs of $\pi$ and $\pi$ and the pair of $\sigma$ and $\sigma$ orbitals on $\mathrm{NO}$, and one combination of $\mathrm{N}(\mathrm{p})$ orbitals of the equatorial pyridine ligands $\left(\sigma_{p y}\right)$. This active space is thus suited to describe all the relevant excited states involved in the photoisomerization mechanism, which all involve $\mathrm{Ru}(\mathrm{d})$ or $\mathrm{Ru}(\mathrm{d})+\mathrm{NO}\left(\pi^{*}\right)$ to $\mathrm{Ru}(\mathrm{d})-\mathrm{NO}\left(\pi^{*}\right)$ transitions (vide infra). State-averaged calculations over seven states were performed separately for singlet and triplet states (denoted $\operatorname{SA7-CASSCF}(16,13)$ ). This number of states is necessary to stabilize the active space. MS-CASPT2 calculations were then performed using a standard IPEA shift ${ }^{64,65}$ of 0.25 a.u. and a level shift of 0.3 a.u. was carefully chosen in order to avoid intruder states. For the first objective, the mixing was allowed between 
all seven singlet states (denoted MS7-CASPT2). Solvent effects were also included using the polarizable continuum model (PCM). Regarding the second and third objectives, separate MSCASPT2 calculations have been performed for each singlet and triplet multiplicity, considering the lowest four states (denoted MS4-CASPT2) for both multiplicities, as only four triplet states are energetically accessible at the irradiation wavelength. The same number of roots for both multiplicities ensures the same deterioration of the wavefunction quality. In all calculations the Douglas-Kroll-Hell Hamiltonian and the Cholesky decomposition with a threshold of $10^{4}$ a.u. were used along with the ANO-RCC-VTZP all-electron basis for Ru and ANO-RCC-VDZP for the other atoms. Oscillator strengths were computed using perturbation modified CASSCF (PM$\mathrm{CASSCF}^{63}$ transition dipole moments along with MS-CASPT2 transition energies. All the MSCASPT2 calculations were performed with MOLCAS 8.0.6

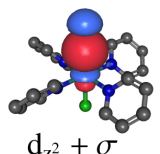

1.982

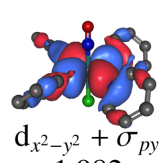

1.982

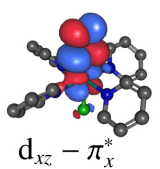

$\mathrm{d}_{x z}-\pi_{x}^{*}$
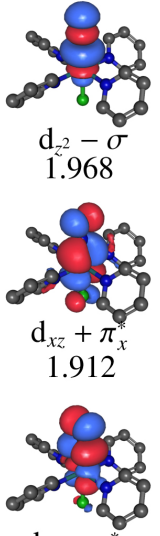

$\mathrm{d}_{y z}-\pi_{y}^{*}$ 0.446

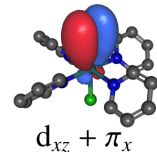

1.958
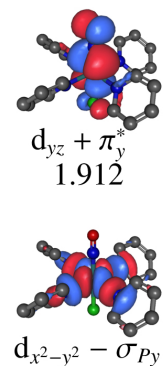

0.039

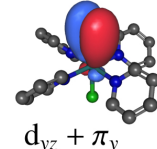

1.958

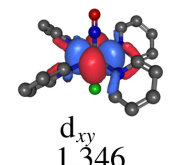

$\mathrm{d}_{x y}$
1.346

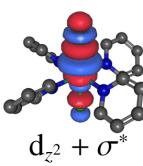

0.030

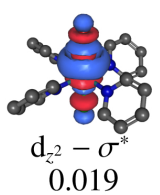

Figure 2. Active orbitals and average occupation numbers obtained from the SA7CASSCF(16,13)/ANO-RCC-VTZP calculation at the GS isomer.

Additional calculations using the strongly-contracted second-order $n$-electron valence state perturbation theory (SC-NEVPT2) method ${ }^{\natural 7}$ were performed to give further support to the MS- 
CASPT2 results. This method has the nice feature that it does not suffer from intruder state problems and the second-order perturbation energy is completely defined once the zeroth-order reference wavefunction is chosen. We have performed SC-NEVPT2 calculations to calculate the $\mathrm{S}_{0} \rightarrow \mathrm{S}_{1}$ vertical transition at GS and MS1 using the same active space as for the MS-CASPT2 calculations but state-averaging over three states only (as $S_{1}$ and $S_{2}$ are degenerate at these geometries). The def2-TZVP basis ${ }^{68}$ on all atoms was used along with the associated small core relativistic pseudopotential ${ }^{6}$ for the $\mathrm{Ru}$ atom. Because the singlet-triplet energy gap is an important feature of the PES due to the involved triplet/singlet crossings along the photoisomerization pathway, the adiabatic $\mathbf{G S} \rightarrow{ }^{\mathbf{G}} \mathbf{G S}$ energy difference was also computed with SC-NEVPT2/def2-TZVP using SA7-CASSCF(16,13) wavefunctions. Domain based local pair natural orbital coupled cluster with single, double and perturbative triple excitations, DLPNO$\operatorname{CCSD}(\mathrm{T}),^{70}$ using the def2-TZVP basis set were performed to investigate the thermal isomerization pathway and the adiabatic $\mathbf{G S} \rightarrow^{3} \mathbf{G S}$ energy difference. SC-NEVPT2 and DLPNO$\operatorname{CCSD}(\mathrm{T})$ calculations were performed with ORCA 4.0.0."1

Regarding the computation of the ISC pathways, the relaxation path on $\mathrm{S}_{1}$ was constructed as a linearly interpolated transit path (LITP) in internal coordinates between the GS isomer equilibrium structure and the optimized geometry of the $\mathrm{S}_{1}$ excited state corresponding to the Nbonded isomer, denoted 'GS. The GS structure was taken from a previous DFT study (using B3LYP with Grimme's dispersion correction; denoted B3LYP+D3 in the following), ,5 while that of 'GS was obtained from a TD-B3LYP geometry optimization (Table S1 in Supporting Information). Along this path, MS4-CASPT2 single-point energy calculations were performed for the lowest four singlet and triplet states (Table S2 in Supporting Information). SOC calculations were performed at selected geometries along the $S_{1}$ relaxation path within the spin- 
orbit state interaction frame,,$^{22}$ using singlet and triplet spin-free CASSCF wavefunctions as basis for the spin-orbit Hamiltonian. Dynamic electron correlation effects were included by using the MS-CASPT2 energies as the diagonal elements of the spin-orbit Hamiltonian.

The thermal isomerization pathway was constructed as a LITP between the various optimized stationary points on the lowest singlet PES (i.e., the GS, MS2 and MS1 minima and the transition states TS1 and TS2 connecting them). These optimized geometries were retrieved from a previous DFT study ${ }_{.5}^{50}$ We have tested the effect of using CASSCF optimized structures. However, due to lack of dynamic correlation at the CASSCF level, the DFT structures proved to be more accurate (Table S3 and Figure S1 in Supporting Information). Similarly, the photoisomerization pathway was obtained from a LITP between the ${ }^{3} \mathbf{G S},{ }^{3} \mathbf{T S 1} 1{ }^{3} \mathbf{M S 2},{ }^{3} \mathbf{T S 1}$ and ${ }^{3}$ MS1 optimized DFT structures. All the MS-CASPT2 energies along these interpolated paths are given in Tables S4 and S5 in Supporting Information. Note that there is a minor change occurring in the active space along these LITP paths. The $d_{x-y^{2}}+\sigma_{p y}$ and $d_{x y^{2} y^{2}}-\sigma_{p y}$ are both replaced by orbitals with similar occupation numbers (Figure S2 in Supporting Information). The main reason is that the original orbitals contribute to a singlet and a triplet excited state in the FC region ( $S_{3}$ and $T_{4}$ in Table 1) but these states become too high in energy along the LITP and are then not included anymore in the state-averaged procedure, thus making these orbitals less relevant. However, this change of active space does not alter the CASSCF and MS-CASPT2 energies significantly (within $0.1 \mathrm{eV}$ ). At MS1, it is possible to find two stable solutions of the active space that differ mainly in the contribution of the $\mathrm{Cl}$ atom (Figure S3 in Supporting Information). Both active spaces lead to very similar potential energy landscapes along the linkage isomerization pathway (Figure S4 in Supporting Information). 


\section{RESULTS AND DISCUSSION}

\subsection{Electronic structures and absorption properties}

Electronic structures. The first seven singlet and triplet electronic states were computed at the GS DFT-optimized geometry using the MS7-CASPT2/ANO-RCC level of theory. Table 1 provides the vertical transition energies and details about the electronic structures of each electronic state, along with oscillator strengths. In all cases, the weights of the leading configuration of the CASSCF wavefunctions, $C^{2}$, are less than 0.9 , indicating a significant multireference character ${ }^{\text {s3 }}$ for some of the states computed, including $S_{0}$ for which the weight of the leading closed-shell configuration is 0.71 .

Table 1. SA7-CASSCF and MS7-CASPT2 transition energies, $\triangle \mathrm{E}(\mathrm{eV})$, nature of the main transitions with their respective weights, and oscillator strengths computed at the GS optimized geometry.

\begin{tabular}{|c|c|c|c|c|c|c|}
\hline State & $\begin{array}{c}\text { CASSCF } \\
\Delta \mathrm{E}\end{array}$ & $\begin{array}{c}\text { MS-CASPT2 } \\
\Delta \mathrm{E}\end{array}$ & Main transition & Nature & $C^{2 a}$ & $\overline{f^{b}}$ \\
\hline \multicolumn{7}{|c|}{ Singlets } \\
\hline $\mathrm{S}_{0}$ & 0.000 & 0.000 & - & - & 0.71 & - \\
\hline$S_{1}$ & 3.076 & 3.028 & $\mathrm{~d}_{x y} \rightarrow \mathrm{d}_{x p}-\pi_{\mathrm{x}}^{*}$ & MLCT & 0.84 & 0.0002 \\
\hline $\mathrm{S}_{2}$ & 3.076 & 3.028 & $\mathrm{~d}_{\mathrm{xy}} \rightarrow \mathrm{d}_{\mathrm{y}}-\pi_{\mathrm{y}}^{*}$ & MLCT & 0.84 & 0.0002 \\
\hline $\mathrm{S}_{3}$ & 3.504 & 3.662 & $\mathrm{~d}_{\mathrm{xy}} \rightarrow \mathrm{d}_{\mathrm{x}^{2} \mathrm{y}^{2}}-\sigma_{\mathrm{py}}$ & $\mathrm{MC}$ & 0.61 & 0.0000 \\
\hline \multirow[t]{2}{*}{$\mathrm{S}_{4}$} & 3.972 & 3.785 & $\mathrm{~d}_{\mathrm{x} 2}+\pi_{\mathrm{x}} \rightarrow \mathrm{d}_{\mathrm{x}}-\pi_{\mathrm{x}}^{\circ}$ & MLCT & 0.43 & 0.0000 \\
\hline & & & $\mathrm{d}_{\mathrm{y} z}+\pi_{y} \rightarrow \mathrm{d}_{\mathrm{y}}-\pi_{y}$ & & 0.43 & \\
\hline \multirow[t]{2}{*}{$\mathrm{S}_{s}$} & 3.984 & 3.955 & $\mathrm{~d}_{\mathrm{p}}+\pi_{\mathrm{y}} \rightarrow \mathrm{d}_{\mathrm{y}}-\pi_{\mathrm{y}}$ & MLCT & 0.49 & 0.0000 \\
\hline & & & $\mathrm{d}_{\mathrm{u}}+\pi_{\mathrm{x}}^{*} \rightarrow \mathrm{d}_{\mathrm{w}}-\pi_{\mathrm{x}}$ & & 0.38 & \\
\hline
\end{tabular}




\begin{tabular}{|c|c|c|c|c|c|c|}
\hline $\mathrm{S}_{6}$ & 3.988 & 3.956 & $\begin{array}{l}\mathrm{d}_{\mathrm{yz}}+\pi_{\mathrm{y}} \rightarrow \mathrm{d}_{\mathrm{p}}-\pi_{\mathrm{y}} \\
\mathrm{d}_{\mathrm{x}}+\pi_{\mathrm{i}} \rightarrow \mathrm{d}_{\mathrm{u}}-\pi_{\mathrm{x}}\end{array}$ & MLCT & $\begin{array}{l}0.42 \\
0.32\end{array}$ & 0.0000 \\
\hline \multicolumn{7}{|c|}{ Triplets } \\
\hline $\mathrm{T}_{1}$ & 2.973 & 2.924 & $\mathrm{~d}_{\mathrm{xy}} \rightarrow \mathrm{d}_{\mathrm{x}}-\pi_{\mathrm{x}}$ & MLCT & 0.87 & 0.0000 \\
\hline $\mathrm{T}_{2}$ & 2.973 & 2.925 & $\mathrm{~d}_{\mathrm{xy}} \rightarrow \mathrm{d}_{\mathrm{y} z}-\pi_{\mathrm{y}}$ & MLCT & 0.87 & 0.0000 \\
\hline $\mathrm{T}_{3}$ & 3.301 & 3.086 & $\begin{array}{l}\mathrm{d}_{\mathrm{w}}+\pi_{\mathrm{x}}^{*} \rightarrow \mathrm{d}_{\mathrm{w}}-\pi_{\mathrm{i}} \\
\mathrm{d}_{\mathrm{p}}+\pi_{\mathrm{v}} \rightarrow \mathrm{d}_{\mathrm{p}}-\pi_{\mathrm{i}}\end{array}$ & MLCT & $\begin{array}{l}0.44 \\
0.44\end{array}$ & 0.0000 \\
\hline $\mathrm{T}_{4}$ & 2.721 & 3.106 & $\mathrm{~d}_{x y} \rightarrow \mathrm{d}_{x^{2}-y^{2}}-\sigma_{p y}$ & $\mathrm{MC}$ & 0.67 & 0.0000 \\
\hline $\mathrm{T}_{5}$ & 3.647 & 3.548 & $\begin{array}{l}\mathrm{d}_{\mathrm{x}}+\pi_{\mathrm{i}} \rightarrow \mathrm{d}_{\mathrm{x}}-\pi_{\mathrm{x}} \\
\mathrm{d}_{\mathrm{y} z}+\pi_{\mathrm{v}} \rightarrow \mathrm{d}_{\mathrm{p}}-\pi_{\mathrm{v}}\end{array}$ & MLCT & $\begin{array}{l}0.44 \\
0.44\end{array}$ & 0.0000 \\
\hline $\mathrm{T}_{6}$ & 3.649 & 3.555 & $\begin{array}{l}\mathrm{d}_{\mathrm{u}}+\pi_{\mathrm{i}}^{*} \rightarrow \mathrm{d}_{\mathrm{u}}-\pi_{\mathrm{v}}^{*} \\
\mathrm{~d}_{\mathrm{p}}+\pi_{\mathrm{y}} \rightarrow \mathrm{d}_{\mathrm{p}}-\pi_{\mathrm{y}}\end{array}$ & MLCT & $\begin{array}{l}0.44 \\
0.44\end{array}$ & 0.0000 \\
\hline $\mathrm{T}_{7}$ & 3.918 & 3.854 & $\begin{array}{l}\mathrm{d}_{\mathrm{x}}+\pi_{\mathrm{x}} \rightarrow \mathrm{d}_{\mathrm{u}}-\pi_{\mathrm{x}} \\
\mathrm{d}_{\mathrm{y} z}+\pi_{\mathrm{y}} \rightarrow \mathrm{d}_{\mathrm{y}}-\pi_{\mathrm{y}}\end{array}$ & MLCT & $\begin{array}{l}0.44 \\
0.44\end{array}$ & 0.0000 \\
\hline
\end{tabular}

${ }^{a} C^{2}$ is the weight of the leading configuration in the SA7-CASSCF wavefunctions. ${ }^{b} f$ is the oscillator strength computed using PM-CASSCF transition dipole moments and MS-CASPT2 energies of the spin-free states.

The first two singlet excited states $S_{1}$ and $S_{2}$ are degenerate by symmetry ('E) and predicted at $3.03 \mathrm{eV}(409 \mathrm{~nm})$ and $2.93 \mathrm{eV}(423 \mathrm{~nm})$ at the MS-CASPT2 and SC-NEVPT2 levels, respectively. Based on the oscillator strengths computed at the MS-CASPT2 level, these two states are the only "bright" states at this geometry among the states computed, although the oscillator strength is very weak (0.0002). This pair of states are obtained by a MLCT transition involving the ruthenium $\mathrm{d}_{x y}$ orbital and a degenerate pair of orbitals mixing $\operatorname{Ru}\left(\mathrm{d}_{x}\right)$ and $\mathrm{NO}\left(\pi_{*}\right)$, and $\operatorname{Ru}\left(\mathrm{d}_{p}\right)$ and $\mathrm{NO}\left(\pi_{v}^{*}\right)$, respectively. This specific transition is notably well documented in the literature. ${ }^{355000}$ The character of the CASSCF transition is in agreement with that of earlier TD- 
DFT calculations (using TPSSh) at the same geometry ${ }^{50}$ and confirms the assignment deduced from the experimental data ${ }^{35}$. However, a higher oscillator strength $(0.003)$ and a lower transition energy $(2.86 \mathrm{eV})$ are obtained at the TD-DFT level in acetonitrile..$^{50}$ The MS-CASPT2 transition computed in acetonitrile gives similar results to the calculation performed in the gas phase (Table $\mathrm{S} 2)$. Note that the irradiation wavelength used experimentally $(473-476 \mathrm{~nm})$ is tuned to optimize the photoconversion efficiency and thus does not correspond necessarily to the maximum of the $\mathrm{S}_{0} \rightarrow \mathrm{S}_{1} / \mathrm{S}_{2}$ absorption band of the crystal. ${ }^{353638}$ In addition, the experimental absorption spectrum recorded in acetonitrile gives this transition at $2.76 \mathrm{eV}(450 \mathrm{~nm}){ }_{7^{74}}$ in reasonable agreement with our MS-CASPT2 calculations. The higher singlet states found are well separated from $S_{1} / S_{2}$, with $\mathrm{S}_{3}$ up to $\mathrm{S}_{6}$ lying between 0.6 to $0.9 \mathrm{eV}$ above $\mathrm{S}_{1} / \mathrm{S}_{2}$. However, it is interesting that $\mathrm{S}_{3}$, a metalcentered (MC) state found at $3.7 \mathrm{eV}$ vertically above the ground state at the MS-CASPT2 level, was found at $4 \mathrm{eV}$ at the TD-DFT level and corresponded to $\mathrm{S}_{20}$ due to many MLCT states being lower in energy..$^{50}$ This is due to the fact that some electronic excited states are missing here due to the limited size of the active space. For example, TD-DFT predicts vertical transition energies to $S_{6}$ and $S_{7}$ corresponding to excitation from a pyridine $\pi$ orbital to $\operatorname{Ru}\left(d_{x 2}\right) / N O\left(\pi_{*}^{*}\right)$ orbitals. As pyridine $\pi$ orbitals have not been included in the active space, these states are not described. However, we describe all the lowest excited states relevant to the photoisomerization mechanism (vide infra).

Regarding the triplet states, $\mathrm{T}_{1}$ and $\mathrm{T}_{2}$ are degenerate by symmetry $\left({ }^{3} \mathrm{E}\right)$ and are located only 0.1 $\mathrm{eV}$ below $\mathrm{S}_{1} / \mathrm{S}_{2}$. These two states are described by transitions involving the same orbitals as in $\mathrm{S}_{1} / \mathrm{S}_{2}(\mathrm{E})$, thus displaying the same MLCT character. The next two triplets $\mathrm{T}_{3}$ and $\mathrm{T}_{4}$ are less than $0.2 \mathrm{eV}$ above $T_{1} / T_{2}$ and less than $0.1 \mathrm{eV}$ above $\mathrm{S}_{1} / \mathrm{S}_{2}$. Note that $\mathrm{T}_{4}$ is a ${ }^{3} \mathrm{MC}$ state. The following triplet states are found substantially higher in energy. Thus, mainly the four lowest triplet states 
are possibly interacting with the initially excited $S_{1} / S_{2}$ states, as the proximity of these states could indeed create appropriate conditions for efficient singlet to triplet intersystem crossings just after light absorption by GS. This hypothesis, already suggested in the preceding DFT studies, ${ }^{50,60}$ will be developed and discussed in the next subsection. Interestingly, the singlet transition energies at the CASSCF level are in good agreement (within $0.2 \mathrm{eV}$ ) with the MSCASPT2 ones; however the order of the states is not correctly reproduced for triplet states.

Absorption properties. Vertical transition energies were also computed at the metastable MS1 and MS2 DFT-optimized geometries in order to describe the low-energy part of the absorption spectra of the three isomers. Inclusion of solvent effects was taken into account for a fair comparison with experiments and previous TD-DFT calculations performed using PCM, as recommended in a recent theoretical work..$^{75}$ All the lowest singlet states carrying non-zero oscillator strengths are listed in Table 2 for all three isomers. The convoluted absorption spectra for the three isomers are shown in Figure 3. As pointed out previously, the limited size of the reference active space prevents the description of all the optical transitions (e.g., those involving $\mathrm{Cl}(\mathrm{p})$ and $\mathrm{py}(\pi)$ orbitals $\left.^{\mathrm{s}^{\circ}}\right)$. Nevertheless, all the relevant excited states for the photoisomerization mechanism (which all involve $\mathrm{Ru}(\mathrm{d})$ or $\mathrm{Ru}(\mathrm{d})+\mathrm{NO}\left(\pi^{*}\right)$ to $\mathrm{Ru}(\mathrm{d})-\mathrm{NO}\left(\pi^{*}\right)$ transitions) are present. In addition, the MS-CASPT2 vertical transition energies agree qualitatively with those obtained by TD-DFT computed in acetonitrile: ${ }^{50}$ i) the order of the states found at the MS-CASPT2 level is the same at the TD-DFT level; ii) the MS-CASPT2 transitions are systematically higher in energy than the TD-DFT ones (within $0.3 \mathrm{eV}$ ) for the bright states.

Table 2. MS7-CASPT2 transition energies, $\Delta \mathrm{E}(\mathrm{eV})$, corresponding wavelengths $(\mathrm{nm})$, nature of the main transitions, and oscillator strengths computed for the three isomers GS, MS2 and MS1. 


\begin{tabular}{|c|c|c|c|c|c|}
\hline Structure & State & $\begin{array}{c}\text { MS-CASPT2 } \\
\Delta \mathrm{E}\end{array}$ & Wavelength & Main transition & $\overline{f^{b}}$ \\
\hline \multirow[t]{2}{*}{ GS } & $S_{1}$ & $3.028(3.101)$ & $409(400)$ & $\mathrm{d}_{\mathrm{xy}} \rightarrow \mathrm{d}_{\mathrm{x}}-\pi_{\mathrm{x}}$ & $0.0002(0.0002)$ \\
\hline & $\mathrm{S}_{2}$ & $3.028(3.101)$ & 409 (400) & $\mathrm{d}_{\mathrm{xy}} \rightarrow \mathrm{d}_{\mathrm{yz}}-\pi_{\mathrm{y}}$ & $0.0002(0.0002)$ \\
\hline \multirow[t]{5}{*}{ MS2 } & $S_{1}$ & $2.054(2.095)$ & $604(592)$ & $\mathrm{d}_{\mathrm{y}}+\pi_{\mathrm{y}}^{*} \rightarrow \mathrm{d}_{\mathrm{x}}-\pi_{\mathrm{x}}^{*}$ & $0.0015(0.0008)$ \\
\hline & $\mathrm{S}_{2}$ & $2.363(2.263)$ & $525(548)$ & $\mathrm{d}_{\mathrm{yz}}+\pi_{\mathrm{y}} \rightarrow \mathrm{d}_{\mathrm{yz}}-\pi_{\mathrm{v}}$ & $0.0001(0.0002)$ \\
\hline & $\mathrm{S}_{3}$ & $2.634(2.648)$ & $471(468)$ & $\mathrm{d}_{\mathrm{xy}} \rightarrow \mathrm{d}_{\mathrm{yz}}-\pi_{\mathrm{y}}$ & $0.0077(0.0075)$ \\
\hline & $\mathrm{S}_{4}$ & $3.035(2.874)$ & 409 (431) & $\mathrm{d}_{x y} \rightarrow \mathrm{d}_{x z}-\pi_{x}^{*}$ & $0.0004(0.0005)$ \\
\hline & $\mathrm{S}_{\mathrm{s}}$ & $3.171(3.193)$ & $391(388)$ & $\mathrm{d}_{x z}+\pi_{\mathrm{x}} \rightarrow \mathrm{d}_{\mathrm{y}}-\pi_{\mathrm{v}}$ & $0.0005(0.0003)$ \\
\hline \multirow[t]{2}{*}{ MS1 } & $S_{1}$ & $1.933(1.944)$ & $641(638)$ & $\mathrm{d}_{\mathrm{xy}} \rightarrow \mathrm{d}_{\mathrm{x}}-\pi_{\mathrm{x}}$ & $0.0001(0.0001)$ \\
\hline & $\mathrm{S}_{2}$ & $1.933(1.944)$ & $641(638)$ & $\mathrm{d}_{\mathrm{xy}} \rightarrow \mathrm{d}_{\mathrm{yz}}-\pi_{\mathrm{y}}^{\cdot}$ & $0.0001(0.0001)$ \\
\hline
\end{tabular}

\footnotetext{
${ }^{a}$ Results obtained in acetonitrile are given in parentheses. ${ }^{b} f$ is the oscillator strength computed using PM-CASSCF transition dipole moments and MS-CASPT2 energies of the spin-free states.
}

The MS2 isomer displays three absorption bands: a weak band centered around $600 \mathrm{~nm}$, a more intense one around $470 \mathrm{~nm}$ and a weak absorption feature at $400 \mathrm{~nm}$. The electronic transition carrying the low energy band corresponds to the $S_{1}$ state and involves a $d_{p z}+\pi_{y}^{*} \rightarrow d_{x z}-$ $\pi_{x}^{*}$ excitation, which was not found among the lowest excited states computed at the GS geometry. The more intense absorption around $470 \mathrm{~nm}$ is associated with $\mathrm{S}_{3}$ and is associated with a $d_{x y} \rightarrow d_{y z}-\pi_{y}^{*}$ transition, which correlates with one component of the doubly degenerate $\mathrm{S}_{1} / \mathrm{S}_{2}$ states at the GS structure. The higher energy absorption feature around $400 \mathrm{~nm}$ is assigned to both $S_{4}$ and $S_{s}$, which exhibit transition wavelength at 409 and $391 \mathrm{~nm}$, respectively. As discussed later, this band plays a critical role in the $\mathrm{N} \rightarrow \mathrm{O}$ linkage photoisomerization mechanism, as it is superimposed with the absorption band of the GS isomer at $409 \mathrm{~nm}$ (Figure 
3). This is in good agreement with the TD-DFT results ${ }^{s^{\circ}}$ obtained in acetonitrile, which also predicted an overlap of the absorption bands between GS and MS2 in this region.

The MS1 isomer shows a weak band around $640 \mathrm{~nm}$. The corresponding transition is of MLCT character and is assigned to a pair of degenerate $\mathrm{S}_{1} / \mathrm{S}_{2}$ states involving similar electronic transitions as the $\mathrm{S}_{1} / \mathrm{S}_{2}$ states of the GS isomer. The MS-CASPT2 transition energy of $1.933 \mathrm{eV}$ is about $0.2 \mathrm{eV}$ higher than the SC-NEVPT2 value at $1.719 \mathrm{eV}(721 \mathrm{~nm})$. This is also in reasonable agreement with the TD-DFT results ${ }^{\mathrm{s}}$ in acetonitrile, which give the same transition at $703 \mathrm{~nm}$, and the irradiation wavelength at $782 \mathrm{~nm}$ used experimentally.4 This band overlaps with the lowenergy absorption band of the MS2 isomer, which is important for the reverse $\mathrm{O} \rightarrow \mathrm{N}$ linkage photoisomerization mechanism. ${ }^{50}$ It is also important to note that MS1 and GS absorb at very different wavelengths, which is an essential requirement for having an efficient photochromic switch.

Regarding the band intensities in Figure 3, it appears that they are underestimated by one order of magnitude for GS and MS1 compared to TD-DFT and experimental observations in acetonitrile. This is probably due to the too weak transition dipole moments computed at the PMCASSCF level. In addition, MS2 displays more intense absorption bands relative to GS and MS1 at the MS-CASPT2 level, a result that was neither observed at the TD-DFT level ${ }^{\text {so }}$ nor experimentally. ${ }^{35}$ Including the SOC or the solvent in the calculations did not alter significantly these absorption spectra, as shown in Figure 3. We tentatively attribute this inconsistency either to inaccurate CASSCF transition dipole moments resulting from a lack of dynamic electron correlation in the CASSCF wavefunctions, or to the incomplete set of active orbitals used. 


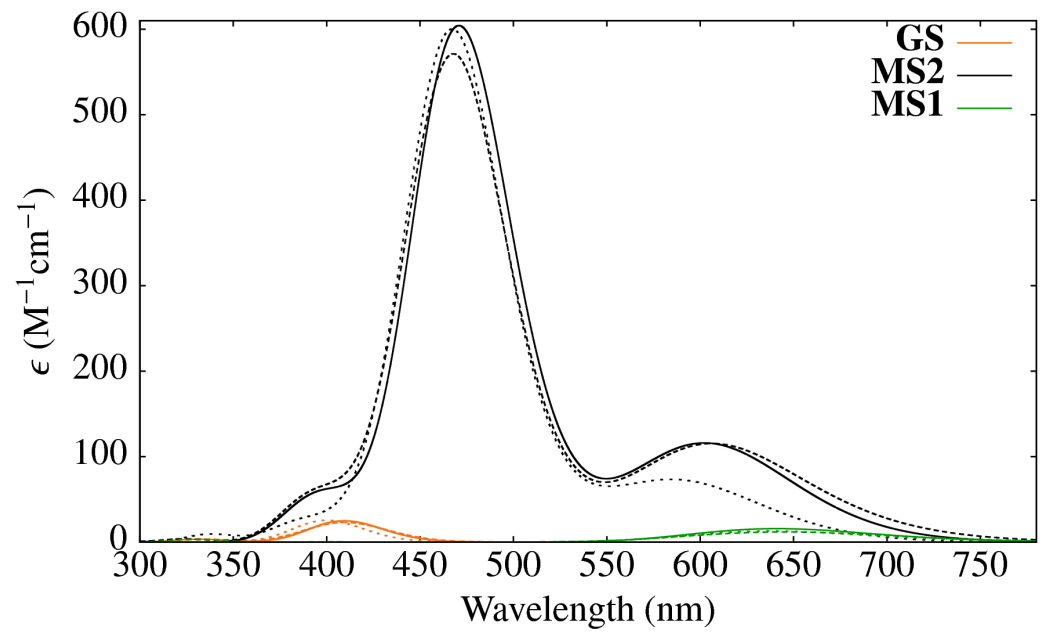

Figure 3. MS7-CASPT2 absorption spectra for the GS, MS2 and MS1 isomers in the gas phase (convoluted arbitrarily with a Gaussian function characterized by a standard deviation of 6000 $\mathrm{cm}^{-1}$. Full lines: spin-free calculations, dashed lines: including spin-orbit couplings, dotted lines: spin-free calculations in acetonitrile.

\subsection{Intersystem crossing pathways}

Investigation of singlet to triplet radiationless transitions is of utmost importance in the $\left[\mathrm{RuCl}(\mathrm{NO})(\mathrm{py})_{4}\right]^{2+}$ photochemistry, as a previous dynamical study on a related system highlighted the efficiency of these transitions ${ }^{60}$ and the whole photoisomerization mechanism proposed in the previous DFT work $^{\text {so }}$ involves several singlet/triplet crossings (Figure 1) and assumed that ultrafast and efficient ISC and IC were taking place from the initially excited 'MLCT states to the lowest ${ }^{3}$ MLCT state. A quantitative study of these non-radiative deactivation processes would require taking into account all the spin-vibronic couplings within a time-dependent approach..$^{4476,67778}$ Here, we simply investigate what are the lowest triplet states of interest susceptible to be populated by ISC using a static picture provided by MS4-CASPT2 and SOC calculations along the initial $S_{1}$ relaxation pathway. 
The MS4-CASPT2 energies are plotted in Figure 4 along the $\mathrm{S}_{1}$ relaxation pathway (data supplied in Table S2 in Supporting Information) and SOC are provided between states lying close to each other. As expected, the lowest excited states $S_{1}$ and $S_{2}$ lose their degeneracy as the molecule leaves the Frank-Condon region. The $S_{1}$ state evolves toward its minimum ( $\mathbf{G S}$ ) along a barrierless potential energy profile, while $S_{2}$ eventually rises in energy. According to these MSCASPT2 calculations, the four lowest triplet states are very close in energy to the lowest singlet excited states $S_{1}$ and $S_{2}$, especially in the vicinity of the Frank-Condon region where they cross each other several times. $T_{3}$ is almost degenerate $\left(0.06 \mathrm{eV}\right.$ gap) with $\mathrm{S}_{1} / \mathrm{S}_{2}$ at the FC geometry. A $\mathrm{S}_{1} / \mathrm{T}_{2}$ crossing is encountered close to the FC geometry (between 0.2 and 0.3 along the LITP) and a $S_{2} / T_{3}$ crossing is present further along the $S_{1}$ relaxation coordinate (between 0.4 and 0.5 along the LITP). Furthermore, the lowest triplet state $T_{1}$ continuously lies below the $S_{1}$ state. Note that the $\mathrm{T}_{1}, \mathrm{~T}_{2}$ and $\mathrm{T}_{4}$ MS-CASPT2 energies are inaccurate at 0.1 along the LITP because of an artificially too strong mixing in the multistate calculation (Table S6 in Supporting Information). This is a well-known MS-CASPT2 issue that can occur near avoided crossings and conical intersections..$^{9}$

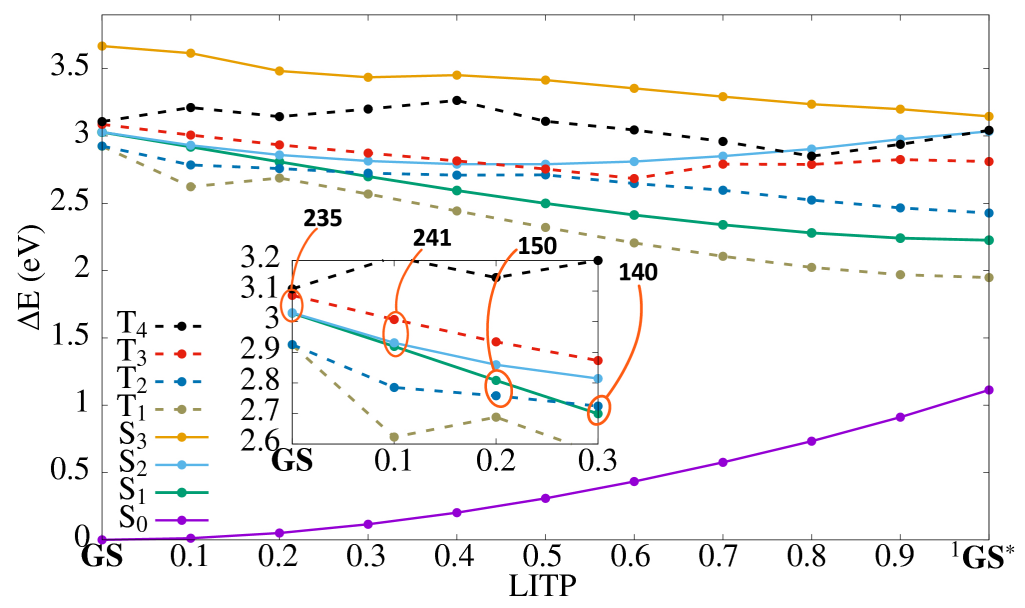

Figure 4. MS4-CASPT2 singlet (full lines) and triplet (dashed lines) potential energy profiles along the $\mathrm{S}_{1}$ relaxation pathway (linearly interpolated transit path: LITP) from the initial GS 
structure to the TD-DFT-optimized $\mathrm{S}_{1}$ minimum ${ }^{\mathbf{}} \mathbf{G S}$. Spin-orbit couplings in $\mathrm{cm}^{-1}$ between pair of states are given in inset.

To get more insight into the possible ISC pathways, SOC calculations were performed at various geometries along the $S_{1}$ relaxation coordinate. The SOC values are shown in inset of Figure 4 between the $S_{1}$ state and the nearest triplet state from the initial GS structure to 0.3 along the LITP. Near the Frank-Condon geometry, the $\mathrm{S}_{1}$ state strongly couples with $\mathrm{T}_{3}$ (SOC $\sim 240 \mathrm{~cm}^{-1}$ at $\mathbf{G S}$ and at 0.1 along the LITP) resulting in a probable $\mathrm{S}_{1} \rightarrow \mathrm{T}_{3}$ ISC. Between 0.2 and 0.3 along the LITP, $S_{1}$ crosses with $T_{2}$ with a substantial SOC between these states $\left(\sim 150 \mathrm{~cm}^{-1}\right)$. The smaller SOC compared to that between $S_{1}$ and $T_{3}$ is compatible with the El-Sayed rule, ${ }^{80}$ in the sense that the $S_{1}$ and $T_{2}$ state share the same character in their electronic transitions (both states are $\left.d \rightarrow d-\pi^{*}\right)$. An $S_{1} \rightarrow T_{2}$ ISC pathway is also very likely. Thus, $S_{1}$ will most likely deactivate non-radiatively to $\mathrm{T}_{2}$ and $\mathrm{T}_{3}$ in the initial relaxation dynamics after irradiation. Because $\mathrm{T}_{3}$ also crosses with $\mathrm{T}_{2}$ (Figure 4), it is likely that $\mathrm{T}_{3}$ will undergo efficient internal conversion to $\mathrm{T}_{2}$. Eventually, $\mathrm{T}_{2}$ is expected to decay to $\mathrm{T}_{1}$, the lowest-lying excited state, but depending on the rate and efficiency of this population transfer, the $\mathrm{T}_{2}$ state (correlating with the $\mathrm{T}_{3} \mathrm{FC}$ state) may still be substantially populated. Thus, according to these calculations, the initial $T_{1}, T_{2}$ and $T_{3}$ MLCT states are all involved in the initial excited-state relaxation dynamics of $\left[\mathrm{RuCl}(\mathrm{NO})(\mathrm{py})_{4}\right]^{2+}$. Note that the ${ }^{3} \mathrm{MC}$ state $\mathrm{T}_{4}$ initially goes up in energy and splits further apart from the $S_{1}$ state, making the $S_{1} \rightarrow T_{4}$ ISC pathway unlikely.

It is also debatable whether part of the initial electronic population would remain on the initial $S_{1}$ and $S_{2}$ singlet excited states. Initially, these two states must be equally populated as they form a Jahn-Teller degeneracy. Because $S_{2}$ is quickly crossing $T_{3}$, its population is expected to decay 
rapidly toward this state (SOC of $186 \mathrm{~cm}^{-1}$ at 0.4 along LITP) and also to the lower $\mathrm{S}_{1}$ state. Relaxation on $\mathrm{S}_{1}$ leads the system to its lowest singlet excited-state N-bonded minimum, 'GS. Again, depending on the rate and efficiency of the ISC channels described above (i.e., $\mathrm{S}_{1} \rightarrow \mathrm{T}_{3}$ and

$S_{1} \rightarrow T_{2}$ ), part of the $S_{1}$ population may remain on this state and relax to ' $\mathbf{G S}$. The consequences of this scenario on the photoisomerization mechanism are described below. However, previous experimental $^{51.5681 .82,83}$ and theoretical ${ }^{57-6084}$ studies point out that ISC pathways are efficient in ruthenium polypyridine complexes. Thus, $S_{1}$ is expected to be depopulated rapidly. In particular, recent nonadiabatic molecular dynamics simulations carried out on a related ruthenium nitrosyl complex demonstrated how the large SOC $\left(\sim 150 \mathrm{~cm}^{-1}\right.$ or more $)$ promotes very efficient ISC, with up to $85 \%$ of trajectories undergoing ultrafast ISC in the first 10 fs. ${ }^{60}$ Our MS-CASPT2 calculations confirm these large SOC and are therefore consistent with efficient ISC channels.

\subsection{Potential energy landscapes}

The previous DFT study focused on the lowest singlet and triplet PES for the whole photoreactive process. ${ }^{50}$ Intervention of higher triplets $\mathrm{T}_{2}$ and $\mathrm{T}_{3}$ was mentioned then but remained hypothetic. The computational strategy involved characterization and optimization of the various minima, transition states and minimum energy crossing points along the photoisomerization pathway. The aim of the present MS-CASPT2 calculations is to reinvestigate the complete mechanism based on a multireference ab initio method capable of describing both static and dynamic electron correlation in a balanced way for all the electronic states involved.

Singlet states. Figure 5 presents the MS4-CASPT2 potential energy profiles for the four lowest singlet states along the ground-state (thermal) isomerization pathway (data provided in Table S4 in Supporting Information). The ground state $\mathrm{S}_{0}$ energy profile appears to be in very good 
agreement with the one obtained at the DFT level. Indeed, all the minima (GS, MS2 and MS1) and transition states connecting them (TS1 and TS2) are found at the MS4-CASPT2 level. Energy gaps are also well reproduced, with a maximum deviation of $\sim 0.3 \mathrm{eV}$ at TS2 between DFT and MS4-CASPT2. Thus, the ab initio results are in line with the previous DFT calculations: the thermal $\mathrm{N} \rightarrow \mathrm{O}$ linkage isomerization cannot be achieved because of large thermodynamic barriers between GS and MS1 on the ground-state PES.

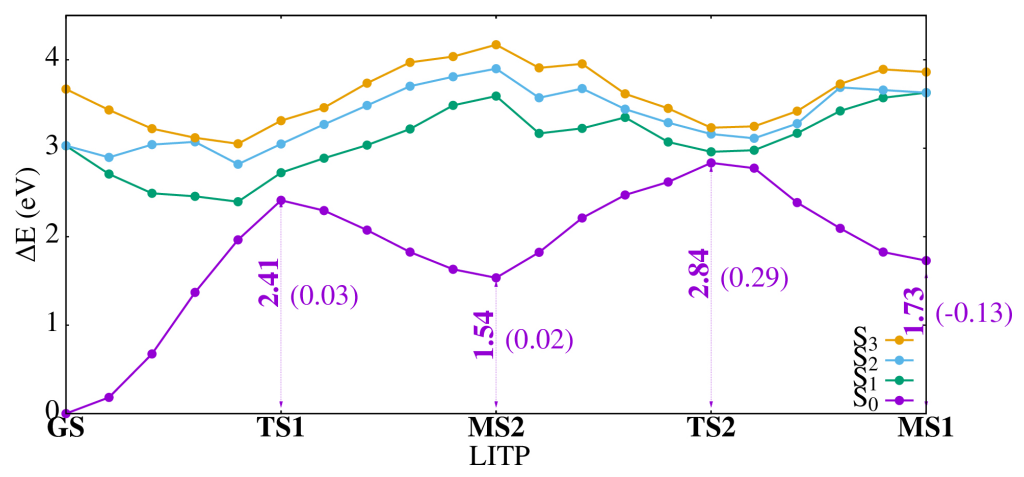

Figure 5. MS4-CASPT2 singlet potential energy profiles along the $S_{0}$ (thermal) linkage isomerization pathway (linearly interpolated transit path: LITP) between GS, TS1, MS2, TS2 and the MS1 DFT-optimized structures. Relative energies are in $\mathrm{eV}$ and values in parentheses are the differences with the DFT values obtained in Ref. [50].

The three lowest excited states $S_{1}, S_{2}$ and $S_{3}$ show a similar behavior in terms of potential energy profiles, which is in contrast to that of $S_{0}$ : When $S_{0}$ is increasing in energy, $S_{1}, S_{2}$ and $S_{3}$ are decreasing, and vice versa. As a result, the energy gap between $S_{0}$ and these excited states is considerably reduced in the transition state regions at TS1 and TS2, so much so that $S_{0}$ and $S_{1}$ become very close in energy. The shape of the potential energy curves suggests two avoided crossings near the two transition states. A detailed examination of the PM-CASSCF wavefunctions $^{63}$ (Figure S5 in Supporting Information) reveals that $S_{0}$ becomes heavily mixed 
around these transition states. Despite the high multiconfigurational character of the ground state in these regions, it is remarkable to note that a single determinant approach like DFT provides good transition state structures and accurate energy barriers. Another interesting feature of the PM-CASSCF wavefunctions is that, while $\mathrm{S}_{0}$ is dominated by a single configuration at $\mathbf{G S}$ and MS2, it is strongly multiconfigurational at MS1 with the largest weight in the configuration expansion being only $43 \%$ for the closed-shell ground-state determinant. In this case, the multiconfigurational character is not due to electronic coupling with the lowest excited states found at the MS1 geometry, as they are well separated in energy with $\mathrm{S}_{0}$ (more than $2 \mathrm{eV}$ higher), but results from mixing with excited states gained in the TS2 region (Figure S5 in Supporting Information). Again, DFT describes the MS1 structure and its relative energy accurately. Note that the reference SA7-CASSCF energy profiles are in good qualitative agreement with MS4CASPT2 for these singlet states (Figure S6 in Supporting Information).

Coupled-cluster DLPNO-CCSD(T) calculations on the $\mathrm{S}_{0}$ ground state confirmed the substantial multiconfigurational character encountered at TS2 and MS1. Compared to the MS4CASPT2 results, relative energy deviations of $0.1 \mathrm{eV}$ up to $0.4 \mathrm{eV}$ are obtained with DLPNO$\operatorname{CCSD}(\mathrm{T})$ (Table S7 in Supporting Information). The T1 diagnostic, which provides a useful indicator for the importance of non-dynamical electron correlation effects, ${ }^{8 s s 6}$ shows the lowest values at GS, TS1, and MS2 geometries, whereas a larger values of 0.021 and 0.019 are obtained at TS2 and MS1, respectively. Thus, according to this diagnostic criterion, significant nondynamical correlation effects are expected at these two geometries and single reference methods like $\operatorname{CCSD}(\mathrm{T})$ and DFT are potentially unreliable. This could explain why the discrepancies between these two levels of theory and MS4-CASPT2 are larger at TS2 and MS1. 
Triplet states. Figure 6 presents the MS4-CASPT2 potential energy profiles for the four lowest triplet states along the adiabatic $\mathrm{T}_{1}$ photoisomerization pathway (data provided in Table S5 in Supporting Information). The overall topology of the $T_{1}$ potential energy profile is again in good agreement with the DFT results. Three minima on the $T_{1}$ PES are located right at the ${ }^{3} \mathbf{G S},{ }^{3} \mathbf{M S 2}$ and ${ }^{3}$ MS1 DFT structures and with the same energetic order: ${ }^{3} \mathbf{M S 2}$ is the highest intermediate standing at ca. $0.9 \mathrm{eV}$ above ${ }^{3} \mathbf{G S}$ and ca. $0.2 \mathrm{eV}$ above ${ }^{3} \mathbf{M S 1}$. These relative energies are within $0.05 \mathrm{eV}$ of the DFT values. Two maxima corresponding to the two transition states ${ }^{3} \mathbf{T S} 1$ and ${ }^{3}$ TS2 are also present at the MS4-CASPT2 level, only slightly shifted with respect to the original position of the optimized transition states with DFT. The associated adiabatic $T_{1}$ potential energy barriers between ${ }^{3} \mathbf{G S}$ and ${ }^{3} \mathbf{M S 2}$, and between ${ }^{3} \mathbf{M S 2}$ and ${ }^{3} \mathbf{M S 1}$ are also in excellent agreement with the DFT values: the first barrier is very high at $1.12 \mathrm{eV}(1.06 \mathrm{eV}$ with DFT), while the second is much lower at $0.27 \mathrm{eV}\left(0.26 \mathrm{eV}\right.$ with DFT). The next triplet states $\mathrm{T}_{2}, \mathrm{~T}_{3}$, and $\mathrm{T}_{4}$, have similar energy profiles to that of $\mathrm{T}_{1}$ except in the region of ${ }^{3} \mathbf{M S 2}$, where their energy raises toward a maximum. Analysis of the PM-CASSCF wavefunctions (Figure S7 in Supporting Information) shows the multiconfigurational character of the triplet states in different regions of the PES. In particular, $T_{1}$ becomes strongly multiconfigurational with the leading electronic configuration weighting less than $80 \%$ of the total wavefunction around ${ }^{3} \mathbf{G S},{ }^{3} \mathbf{T S 1}$ and ${ }^{3} \mathbf{T S 2}$. Remarkably, the $\mathrm{T}_{1}$ electronic structure changes from ${ }^{3} \mathbf{G S}$ to ${ }^{3} \mathbf{T S 1}$ to ${ }^{3} \mathbf{M S 2}$ due to various couplings with the higher triplet states. In particular, ${ }^{3} \mathbf{T S 1}$ and ${ }^{3} \mathbf{T S 2}$ correspond to regions of weakly avoided crossings between $T_{1}$ and higher triplet states. This is reminiscent to what was found between $S_{0}$ and higher singlet states at TS1 and TS2. Note, however, that unlike singlet states, triplet states are in many occasions well represented by only one configuration with a weight greater than $80 \%$. In addition, while the reference SA7-CASSCF energy profiles were in 
good qualitative agreement with MS4-CASPT2 for the lowest four singlet states, SA7-CASSCF gives a qualitatively wrong picture for the lowest triplet PES for which ${ }^{3} \mathbf{M S 2}$ appears as a transition state rather than a minimum along the photoisomerization pathway (Figure S8 in Supporting Information).

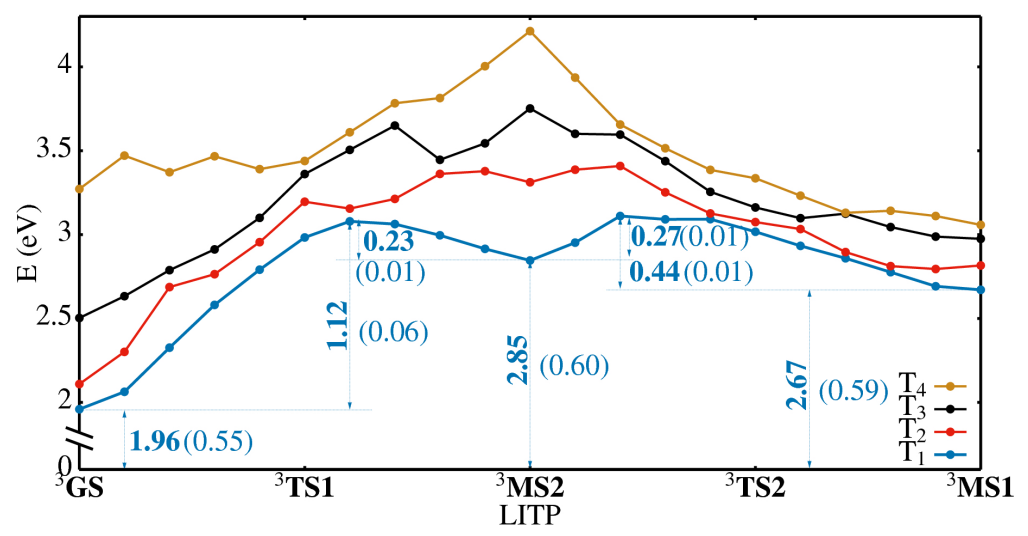

Figure 6. MS4-CASPT2 triplet potential energy profiles along the adiabatic $T_{1}$ linkage photoisomerization pathway (linearly interpolated transit path: LITP) between ${ }^{3} \mathbf{G S},{ }^{3} \mathbf{T S 1},{ }^{3} \mathbf{M S 2}$, ${ }^{3}$ TS2 and the ${ }^{3}$ MS1 DFT-optimized structures. Relative energies are in $\mathrm{eV}$ and values in parentheses are the differences with the DFT values obtained in Ref. [50].

Triplet/singlet crossings. Despite the excellent agreement between MS-CASPT2 and DFT regarding the adiabatic singlet and triplet potential energy profiles, there is one major discrepancy concerning the $\mathrm{S}_{0}-\mathrm{T}_{1}$ energy gap. At the MS-CASPT2 level, the $\mathrm{T}_{1}$ PES is shifted up in energy by about $0.6 \mathrm{eV}$ relative to the $\mathrm{S}_{0}$ PES compared to DFT (see Figure 6). As a result, the ${ }^{3} \mathbf{G S}$ minimum lies $1.96 \mathrm{eV}$ above the GS minimum, instead of $1.42 \mathrm{eV}$ with DFT, and a similar shift occurs for the whole $T_{1}$ PES. The better accuracy of the MS-CASPT2 singlet-triplet energy gap over B3LYP is confirmed by DLPNO-CCSD(T) and SC-NEVPT2 results, which predict a GS to ${ }^{3} \mathbf{G S}$ adiabatic transition at 1.85 and $2.18 \mathrm{eV}$, respectively. This large change in the $\mathrm{S}_{0}-\mathrm{T}_{1}$ 
relative energies between B3LYP and MS-CASPT2 has important consequences on the position of the triplet/singlet crossing points. As described in the introduction, these funnels play an important role in the sequential two-photon photoisomerization mechanism derived from the DFT results.. ${ }^{50}$ To locate these crossing points at the MS-CASPT2 level, we show in Figure 7 the potential energy profiles of the singlet states along the adiabatic $T_{1}$ linkage photoisomerization pathway. While four $T_{1} / S_{0}$ minimum energy crossing points were optimized along this pathway at the DFT level (see Figure 1 and Ref. [50]), only two $T_{0} / S_{0}$ crossing points are found with MSCASPT2. The first one is encountered between ${ }^{3} \mathbf{G S}$ and ${ }^{3} \mathbf{T S} 1$ and lies about $0.25 \mathrm{eV}$ above ${ }^{3} \mathbf{G S}$. The second one is located very close to ${ }^{3} \mathbf{M S 1}$ only $0.02 \mathrm{eV}$ above this minimum. The first MSCASPT2 crossing point corresponds to the second minimum energy crossing point located with DFT at $0.67 \mathrm{eV}$ above ${ }^{3} \mathbf{G S}$. The second MS-CASPT2 crossing point corresponds to the fourth minimum energy crossing point located with DFT at $0.17 \mathrm{eV}$ above ${ }^{3} \mathrm{MS1}$. The consequences of these differences in the position of the $T_{1} / S_{0}$ funnels on the photoisomerization mechanism are discussed in the following subsection.

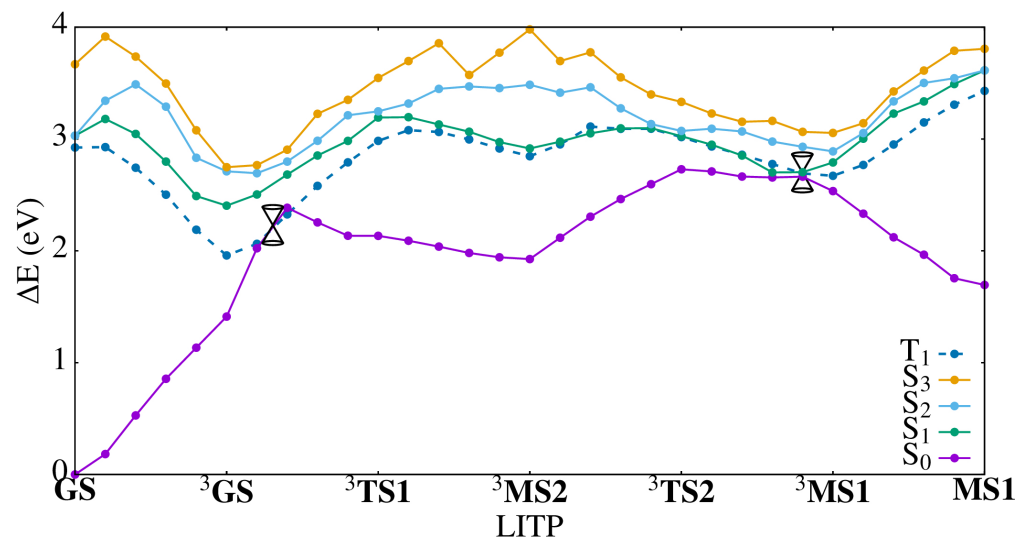

Figure 7. MS4-CASPT2 $\mathrm{S}_{0}-\mathrm{S}_{3}$ (full lines) and $\mathrm{T}_{1}$ (dashed line) potential energy profiles along the adiabatic $T_{1}$ linkage photoisomerization pathway (linearly interpolated transit path: LITP) 
between GS, ${ }^{3} \mathbf{G S},{ }^{3} \mathbf{T S 1} 1,{ }^{3} \mathbf{M S 2},{ }^{3} \mathbf{T S 2},{ }^{3} \mathbf{M S 1}$ and the MS1 DFT-optimized structures. Double-cone pictograms represent $T_{1} / S_{0}$ crossing points.

\section{$3.4 \mathrm{~N} \rightarrow \mathrm{O}$ linkage photoisomerization mechanism revisited}

After irradiation of the GS isomer with a blue light photon, the degenerate pair of singlet excited states $\mathrm{S}_{1} / \mathrm{S}_{2}$ of $\mathrm{d} \rightarrow \mathrm{d} \pi^{*}$ nature are populated. As discussed in subsection 3.2, efficient ISC pathways were identified driving the system to lower ${ }^{3}$ MLCT states, $T_{1}$ and possibly $T_{2}$. The adiabatic $T_{1}$ PES displays an unfavorable energetic landscape along the $\mathrm{N} \rightarrow \mathrm{O}$ linkage photoisomerization with a high activation energy $(>1 \mathrm{eV})$ and an energetically uphill process $\left(\Delta \mathrm{E}{ }^{3} \mathbf{G S} \rightarrow{ }^{3} \mathbf{M S 1}=0.7 \mathrm{eV}\right)$. However, two funnels for efficient ISC between $T_{1}$ and $\mathbf{S}_{\circ}$ were located, providing much more favorable nonadiabatic photoisomerization pathways. Upon relaxation to $\mathbf{G S}$, the system can reach a first $T_{1} / S_{0}$ crossing only $0.25 \mathrm{eV}$ above ${ }^{3} \mathbf{G S}$. Nonradiative $T_{1} \rightarrow S_{0}$ decay can then bring the system to the MS2 isomer. As this intermediate also absorbs light in the same blue region of the spectrum as GS, this species is photoexcited to 'MLCT excited states ( $\mathrm{S}_{4}$ in this case; Table 2). Upon relaxation down to the lowest triplet state (assuming efficient radiationless decay mechanisms as the ones shown at the FC region of the GS isomer), the ${ }^{3} \mathbf{M S 2}$ intermediate is expected to be populated. Subsequently, a low energy barrier $(0.27 \mathrm{eV})$ has to be surmounted to complete the isomerization towards to O-bonded isomer ${ }^{3} \mathrm{MS1}$. In the vicinity of this excited-state minimum, a second $\mathrm{T}_{\imath} / \mathrm{S}_{0}$ crossing only $0.02 \mathrm{eV}$ above ${ }^{3}$ MS1 was located, allowing for efficient ISC down to the photoproduct MS1.

This mechanism is similar to the sequential two-photon absorption mechanism described in a previous DFT study ${ }^{50}$ Note however, that the nonadiabatic photoisomerization pathway proposed here is more favorable than that issued from the DFT calculations. Indeed, at the B3LYP+D3 
level, a minimum energy triplet/singlet crossing point was located right at the bottom of the ${ }^{3} \mathbf{G S}$ potential energy well, providing an efficient funnel for the photostabilization of GS (Figure 1). Due to the energy shift of the $T_{1}$ PES with respect to the $S_{0}$ PES, this crossing is removed at the MS-CASPT2 level (Figure 7) and the first located funnel is productive for photoisomerization, as it allows for non-radiative decay to the MS2 isomer. In addition, once the second photon has been absorbed and the system has relaxed to the ${ }^{3} \mathbf{M S 2}$ intermediate, another minimum energy triplet/singlet crossing point was identified at the B3LYP+D3 level, which provides a photostabilization pathway for MS2 (Figure 1). This funnel does not exist at the MS-CASPT2 level, resulting in a more efficient ${ }^{3} \mathbf{M S 2} \rightarrow{ }^{\mathbf{3}} \mathbf{M S 1}$ adiabatic pathway. Finally, the triplet/singlet funnel located in the photoproduct region is found at the bottom of the ${ }^{\text {s }}$ SS1 potential energy well at the MS-CASPT2 level, allowing for an efficient ${ }^{3}$ MS1 $\rightarrow$ MS1 ISC. Note that the SOC at the first and second triplet/singlet crossings are $28 \mathrm{~cm}^{-1}$ and $20 \mathrm{~cm}^{-1}$, respectively. These values are about one order of magnitude smaller than those found between $S_{1}$ and $T_{3}$ (Figure 4). It can be simply explained by the El-Sayed rule, ${ }^{\text {so }}$ as $S_{\circ}$ and $T_{1}$ both involve a $d+\pi^{*} \rightarrow d-\pi^{*}$ transition at these two crossing geometries (Table S8 in Supporting Information).

Another remarkable observation is that the second part of the isomerization mechanism following absorption of a second blue light photon could possibly occur on the $\mathrm{S}_{1}$ singlet excited state. Indeed, Figure 7 shows that the $T_{1}$ and $S_{1}$ PES between ${ }^{3}$ MS2 and ${ }^{3}$ MS1 are quasi degenerate, allowing for efficient ISC between $T_{1}$ and $S_{1}$ due to significant SOC (Table $S 9$ in Supporting Information). Analysis of the CASSCF wavefunctions shows that both electronic states are made of the same electronic configurations over a large segment along this potential energy profile. 
It is also interesting to note that, in the less probable scenario where part of the electronic population would survive long enough on the initially excited $\mathrm{S}_{1}$ state to undergo a complete singlet photoisomerization, the potential energy landscape shown in Figure 5 would guarantee an efficient sequential two-photon absorption singlet mechanism as well. Indeed, upon relaxation from the FC region in the $S_{1}$ state, it is clear that the system would decay back to $S_{0}$ in a downhill process by efficient IC in the region of TS1 where the singlet electronic states strongly couple. This would lead to efficient formation of MS2, which upon absorption of a second photon would bring the system to $S_{4}$. Here, the system could decay back to $S_{0}$ in another region of strong electronic coupling at TS2, leading to the final MS2 photoproduct.

\section{CONCLUSION}

We have investigated the $\mathrm{N} \rightarrow \mathrm{O}$ linkage photoisomerization mechanism in the $\left[\mathrm{RuCl}(\mathrm{NO})(\mathrm{py})_{4}\right]^{2+}$ complex using accurate MS-CASPT2 calculations in order to confirm previous interpretations based on DFT calculations ${ }^{\text {s }}$ and recent experimental observations." Our results provide further evidence that a multistep sequential two-photon photoisomerization mechanism requiring several ISC processes is involved. The first $473 \mathrm{~nm}$ photon absorption from the stable N-bonded GS isomer triggers a partial linkage isomerization leading to the side-on (NO-bonded) metastable MS2 isomer. This first isomerization step involves an efficient ISC pathway from the initially populated 'MLCT excited states to the lowest ${ }^{3}$ MLCT excited state. Vibrational relaxation of this state leads to a $\mathrm{N}$-bonded triplet intermediate (denoted ${ }^{3} \mathbf{G S}$ ) from which an adiabatic isomerization is forbidden because of the large potential energy barrier $(>1 \mathrm{eV})$ encountered on the corresponding triplet PES. The most probable route takes place through an ISC channel via a triplet/singlet funnel leading to the MS2 isomer. This isomer absorbs 
efficiently at the same wavelength and the second $473 \mathrm{~nm}$ photon absorption induces the completion of the $\mathrm{N} \rightarrow \mathrm{O}$ linkage isomerization. This second isomerization step involves ISC from 'MLCT states to the lowest triplet states, followed by relaxation to a NO-bonded triplet intermediate (denoted ${ }^{3}$ MS2) from which adiabatic isomerization to an O-bonded triplet species (denoted ${ }^{3}$ MS1) is possible. The formation of the singlet ground-state photoproduct, the Obonded MS1, is achieved through an ISC channel occurring at another triplet/singlet funnel in the photoproduct region of the PES. Note that we cannot exclude that this second part of the photoisomerization process takes place in the singlet excited state due to the proximity between the $\mathrm{S}_{1}$ and $\mathrm{T}_{1}$ states between ${ }^{3} \mathbf{M S 2}$ and ${ }^{3} \mathbf{M S 1}$. The potential energy landscape of the singlet states would also allow for a complete sequential two-photon absorption singlet photoisomerization mechanism. However, due to the high probability of ISC with lower triplet states, the mixed singlet/triplet scenario described above is more likely.

Overall, the $\mathrm{N} \rightarrow \mathrm{O}$ linkage photoisomerization mechanism is similar to the one obtained from DFT calculations, as they both predict a multistep sequential two-photon photoisomerization mechanism. ${ }^{30}$ However, a significant difference results from the position of the triplet/singlet funnels due to the higher energy gap between the singlet and triplet PES. At the B3LYP+D3 level, four funnels were located. Two of them were photostabilizing (i.e., GS and MS2, respectively), while the other two were photoreactive (i.e., allowing for the first and second isomerization steps). At the CASPT2 level, there are only two crossings left, which play the role of photochemical funnels. We hope that this work will stimulate further experimental and theoretical studies in order to clarify the role of these highly intertwined singlet and triplet electronic states. In particular, time-resolved absorption spectroscopy and nonadiabatic dynamics 
simulations could bring additional insights into the transient species populated along the $\mathrm{N} \rightarrow \mathrm{O}$ linkage photoisomerization. 


\section{ASSOCIATED CONTENT}

Supporting Information. The following file is available free of charge: Table S1 for ' $\mathbf{G S}$ optimized TD-DFT Cartesian coordinates. Table S2 for MS4-CASPT2 energies along the S, relaxation pathway $\mathbf{G S} \rightarrow \mathbf{G S}$. Table S3 for DFT and CASSCF optimized geometries of $\mathbf{G S .}$ Figure S1 for MS-CASPT2 energies at DFT and CASSCF optimized geometries of GS. Table S4 for MS4-CASPT2 energies along the thermal isomerization pathway. Table S5 for MS4CASPT2 energies along the photoisomerization pathway. Figure S2 for change of active space along the LITP. Figure S3 for different SA7-CASSCF $(16,13)$ stable active orbitals at MS1. Figure S4 for MS4-CASPT2 thermal isomerization pathway using alternative active space. Table S6 for mixing coefficients in MS-CASPT2 calculations. Figure S5 for PM-CASSCF main electronic characters along the thermal isomerization pathway. Figure S6 for CASSCF singlet energy profiles along the thermal isomerization pathway. Table S7 for DLPNO-CCSD(T) relative energies along the thermal isomerization pathway. Figure S7 for PM-CASSCF main electronic characters along the photoisomerization pathway. Figure S8 for CASSCF triplet energy profiles along the photoisomerization pathway. Table $S 8$ for $S_{0}$ and $T_{1}$ configurations at the triplet/singlet funnels. Table S9 for SOC between $S_{1}$ and $T_{1}$ along the ${ }^{3} \mathbf{M S 2} \rightarrow{ }^{3} \mathbf{M S 1}$ pathway. (PDF)

\section{AUTHOR INFORMATION}

\section{Corresponding Author}

*E-mail: martial.boggio@irsamc.ups-tlse.fr

\section{ORCID}


Martial Boggio-Pasqua: 0000-0001-6684-5223

\section{Funding Sources}

We acknowledge the financial support of the ITN-EJD-TCCM PhD Fellowship as part of the Marie Skłodowska-Curie Actions (European Union’s Horizon 2020 research and innovation programme under the Marie Curie Skłodowska-Curie grant agreement No.642294).

\section{Notes}

The authors declare no competing financial interest.

\section{ACKNOWLEDGMENT}

This work was granted access to the HPC resources of CALMIP supercomputing center under the allocation 2017-[0880].

\section{REFERENCES}

' Irie, M. Diarylethenes for Memories and Switches. Chem. Rev. 2000, 100, 1685-1716.

2Yokoyama, Y. Fulgides for Memories and Switches. Chem. Rev. 2000, 100, 1717-1739.

${ }^{3}$ Berkovic, G.; Krongauz, V.; Weiss, V. Spiropyrans and Spirooxazines for Memories and Switches. Chem. Rev. 2000, 100, 1741-1753.

${ }^{4}$ Szaciłowski, K. Digital Information Processing in Molecular Systems. Chem. Rev. 2008, 108, $3481-3548$. 
${ }^{5}$ Pischel, U.; Andréasson, J.; Gust, D.; Pais, V. F. Information Processing with MoleculesQuo Vadis? ChemPhysChem 2013, 14, 28-46.

- Al-Atar, U.; Fernandes, R.; Johnsen, B.; Baillie, D.; Branda, N. R. A Photocontrolled Molecular Switch Regulates Paralysis in a Living Organism. J. Am. Chem. Soc. 2009, 131, $15966-15967$.

Szymański, W.; Beierle, J. M.; Kistemaker, H. A. V.; Velema, W. A.; Feringa, B. L. Reversible Photocontrol of Biological Systems by the Incorporation of Molecular Photoswitches. Chem. Rev. 2013, 113, 6114-6178.

${ }^{8}$ Feringa, B. L. The Art of Building Small: From Molecular Switches to Molecular Motors. $J$. Org. Chem. 2007, 72, 6635-6652.

9 Kim, T.; Zhu, L.; Al-Kaysi, R. O.; Bardeen, C. J. Organic Photomechanical Materials, ChemPhysChem 2014, 15, 400-414.

${ }_{10}$ Dürr, H.; Bouas-Laurent, H., Eds, Photochromism: Molecules and Systems; Elsevier: Amsterdam, 2003.

"Bouas-Laurent, H.; Dürr, H. Organic Photochromism. Pure Appl. Chem. 2001, 73, 639-665.

${ }_{12}$ Crano, J. C.; Guglielmetti, R. J., Eds, Organic Photochromic and Thermochromic Compounds, Kluwer Academic Publishers: New York, 2002.

${ }^{13}$ Coppens, P.; Novozhilova, I.; Kovalevsky, A. Photoinduced Linkage Isomers of TransitionMetal Nitrosyl Compounds and Related Complexes. Chem. Rev. 2002, 102, 861-883. 
${ }_{14}$ Bitterwolf, T. E. Photochemical Nitrosyl Linkage Isomerism/Metastable States. Coord. Chem. Rev. 2006, 250, 1196-1207.

${ }^{15}$ Rack, J. J. Electron Transfer Triggered Sulfoxide Isomerization in Ruthenium and Osmium Complexes, Coord. Chem. Rev. 2009, 253, 78-85.

${ }^{16}$ McClure, B. A.; Rack, J. J. Isomerization in Photochromic Ruthenium Sulfoxide Complexes. Eur. J. Inorg. Chem. 2010, 3895-3904.

${ }^{17}$ Sylvester, S. O.; Cole, J. M.; Waddell, P. G. Photoconversion Bonding Mechanism in Ruthenium Sulfur Dioxide Linkage Photoisomers Revealed by in Situ Diffraction . J. Am. Chem. Soc. 2012, 134, 11860-11863.

${ }^{18}$ Vieuxmaire, O. P. J.; Piau, R. E.; Alary, F.; Heully, J.-L.; Sutra, P.; Igau, A.; Boggio-Pasqua, M. Theoretical Investigation of Phosphinidene Oxide Polypyridine Ruthenium(II) Complexes: Toward the Design of a New Class of Photochromic Compounds. J. Phys. Chem. A 2013, 117, $12821-12830$.

${ }_{19}$ Woike, Th.; Haussühl, S. Infrared-Spectroscopic and Differential Scanning Calorimetric Studies of the Two Light-Induced Metastable States in $\mathrm{K}_{2}\left[\mathrm{Ru}\left(\mathrm{NO}_{2}\right)_{4}(\mathrm{OH})(\mathrm{NO})\right]$. Solid State Commun. 1993, 86, 333-337.

${ }^{20}$ Fomitchev, D. V.; Coppens, P. X-ray Diffraction Analysis of Geometry Changes upon Excitation: The Ground-State and Metastable-State Structures of $\mathrm{K}_{2}\left[\mathrm{Ru}\left(\mathrm{NO}_{2}\right)_{4}(\mathrm{OH})(\mathrm{NO})\right]$. Inorg . Chem. 1996, 35, 7021-7026. 
${ }^{21}$ Ford, P. C.; Bourassa, J.; Miranda, K.; Lee, B.; Lorkovic, I.; Boggs, S.; Kudo, S.; Laverman, L. Photochemistry of Metal Nitrosyl Complexes. Delivery of Nitric Oxide to Biological Targets. Coord. Chem. Rev. 1998, 171, 185-202.

${ }^{22}$ Fomitchev, D. V.; Coppens, P.; Li, T.; Bagley, K. A.; Chen, L.; Richter-Addo, G. B. Photoinduced metastable linkage isomers of ruthenium nitrosyl porphyrins. Chem. Commun. 1999, 2013-2014.

${ }^{23}$ Da Silva, S. C.; Franco, D. W. Metastable Excited State and Electronic Structure of $\left[\mathrm{Ru}\left(\mathrm{NH}_{3}\right)_{5} \mathrm{NO}\right]^{3+}$ and $\left[\mathrm{Ru}\left(\mathrm{NH}_{3}\right)_{4}(\mathrm{OH}) \mathrm{NO}\right]^{2+}$. Spectrochim. Acta A 1999, 55, 1515-1525.

${ }^{24}$ Gorelsky, S. I.; Lever, A. B. P. Metastable States of Ruthenium (II) Nitrosyl Complexes and Comparison with $\left[\mathrm{Fe}(\mathrm{CN})_{5} \mathrm{NO}\right]^{2-}$. Int. J. Quantum Chem. 2000, 80, 636-645.

${ }_{25}$ Tfouni, E.; Krieger, M.; McGarvey, B. R.; Franco, D. W. Structure, Chemical and Photochemical Reactivity and Biological Activity of Some Ruthenium Amine Nitrosyl Complexes. Coord. Chem. Rev. 2003, 236, 57-69.

${ }^{26}$ Ferlay, S.; Schmalle, H. W.; Francese, G.; Stoeckli-Evans, H.; Imlau, M.; Schaniel, D.; Woike, T. Light-Induced Metastable States in Oxalatenitrosylruthenium(II) and Terpyridinenitrosylruthenium(II) Complexes. Inorg. Chem. 2004, 43, 3500-3506.

${ }_{27}$ Schaniel, D.; Woike, T.; Boskovic, C.; Güdel, H.-U. Evidence for two light-induced metastable states in $\mathrm{Cl}_{3}\left[\mathrm{Ru}\left(\mathrm{NH}_{3}\right)_{5} \mathrm{NO}\right] \mathrm{H}_{2} \mathrm{O}$. Chem. Phys. Lett. 2004, 390, 347-351.

${ }^{28}$ Szundi, I.; Rose, M. J.; Sen, I.; Eroy-Reveles, A. A.; Mascharak, P. K.; Einarsdóttir, Ó. A New Approach for Studying Fast Biological Reactions Involving Nitric Oxide: Generation of 
NO Using Photolabile Ruthenium and Manganese NO Donors, Photochem. Photobiol. 2006, 82, 1377-1384.

${ }_{29}$ Bitterwolf, T. E. Photolysis of $\left[\mathrm{Ru}(\text { bipy })_{2}(\mathrm{NO}) \mathrm{Cl}\right]\left(\mathrm{PF}_{6}\right)_{2}$ in Frozen Ionic Glass Matrices. Evidence for Nitrosyl Linkage Isomerism and NO-Loss in a Physiologically Relevant Nitric Oxide Source. Inorg. Chem. Commun. 2008, 11, 772-773.

${ }^{30}$ Rose, M. J.; Mascharak, P. K. Photoactive Ruthenium Nitrosyls: Effects of Light and Potential Application as NO Donors. Coord. Chem. Rev. 2008, 252, 2093-2114.

${ }^{31}$ Rose, M. J.; Fry, N. L.; Marlow, R.; Hink, L.; Mascharak, P. K. Sensitization of Ruthenium Nitrosyls to Visible Light via Direct Coordination of the Dye Resorufin: Trackable NO Donors for Light-Triggered NO Delivery to Cellular Targets, J. Am. Chem. Soc. 2008, 130, 8834-8846.

${ }^{32}$ Giglmeier, H.; Kerscher, T.; Klüfers, P.; Schaniel, D.; Woike, T. Nitric-Oxide Photorelease and Photoinduced Linkage Isomerism on Solid $[\mathrm{Ru}(\mathrm{NO})($ terpy $)(\mathrm{L})] \mathrm{BPh}_{4}(\mathrm{~L}=$ glycolate dianion). Dalton Trans. 2009, 9113-9116.

${ }^{33}$ Ostrowski, A. D.; Ford, P. C. Metal Complexes as Photochemical Nitric Oxide Precursors: Potential Applications in the Treatment of Tumors. Dalton Trans. 2009, 10660-10669.

${ }^{34}$ Zangl, A.; Klüfers, P.; Schaniel, D.; Woike, T. Photoinduced Linkage Isomerism of $\{\text { RuNO }\}^{6}$ Complexes with Bioligands and Related Chelators. Dalton Trans. 2009, 6, 1034-1045.

${ }^{35}$ Schaniel, D.; Cormary, B.; Malfant, I.; Valade, L.; Woike, T.; Delley, B.; Krämer, K. W.; Güdel, H.-U. Photogeneration of Two Metastable NO Linkage Isomers with High Populations of up to $76 \%$ in trans- $\left[\mathrm{RuCl}(\mathrm{py})_{4}(\mathrm{NO})\right]\left[\mathrm{PF}_{6}\right]_{2} \cdot 1 / 2 \mathrm{H}_{2} \mathrm{O}$. Phys. Chem. Chem. Phys. 2007, 9, 3717-3724. 
${ }^{36}$ Cormary, B.; Malfant, I.; Buron-Le Cointe, M.; Toupet, L.; Delley, B.; Schaniel, D.; Mockus, N.; Woike, T.; Fejfarová, K.; Petříček, V.; Dušek, M. [Ru(py) $\left.{ }_{4} \mathrm{Cl}(\mathrm{NO})\right]\left(\mathrm{PF}_{6}\right)_{2} \cdot 0.5 \mathrm{H}_{2} \mathrm{O}$ : A Model System for Structural Determination and Ab Initio Calculations of Photo-Induced Linkage NO Isomers. Acta Cryst. B 2009, 65, 612-623.

${ }^{37}$ Fry, N. L.; Mascharak, P. K. Photoactive Ruthenium Nitrosyls as NO Donors: How to Sensitize Them toward Visible Light. Acc. Chem. Res. 2011, 44, 289-298.

${ }^{38}$ Cormary, B.; Ladeira, S.; Jacob, K.; Lacroix, P. G.; Woike, T.; Schaniel, D.; Malfant, I. Structural Influence on the Photochromic Response of a Series of Ruthenium Mononitrosyl Complexes. Inorg. Chem. 2012, 51, 7492-7501.

${ }^{39}$ Akl, J.; Sasaki, I.; Lacroix, P. G.; Malfant, I.; Mallet-Ladeira, S.; Vicendo, P.; Farfán, N.; Santillan, R. Comparative Photo-Release of Nitric Oxide from Isomers of Substituted Terpyridinenitrosyl-Ruthenium(II) Complexes: Experimental and Computational Investigations. Dalton Trans. 2014, 43, 12721-12733.

${ }^{40}$ deBoer, T. R.; Mascharak, P. K. Recent Progress in Photoinduced NO Delivery With Designed Ruthenium Nitrosyl Complexes. Adv. Inorg. Chem. 2015, 67, 145-170.

${ }^{4}$ Khadeeva, L.; Kaszub, W.; Lorenc, M.; Malfant, I.; Buron-Le Cointe, M. Two-Step Photon Absorption Driving the Chemical Reaction in the Model Ruthenium Nitrosyl System $\left[\mathrm{Ru}(\mathrm{py})_{4} \mathrm{Cl}(\mathrm{NO})\right]\left(\mathrm{PF}_{6}\right)_{2} \cdot 1 / 2 \mathrm{H}_{2} \mathrm{O}$. Inorg. Chem. 2016, 55, 4117-4123. 
${ }^{42}$ Tassé, M.; Mohammed, H. S.; Sabourdy, C.; Mallet-Ladeira, S.; Lacroix, P. G.; Malfant, I. Synthesis, Crystal Structure, Spectroscopic, and Photoreactive Properties of a Ruthenium(II)Mononitrosyl Complex. Polyhedron 2016, 119, 350-358.

${ }_{43}$ Sanz García, J.; Alary, F.; Boggio-Pasqua, M.; Dixon, I. M.; Heully, J.-L. Is photoisomerization required for NO photorelease in ruthenium nitrosyl complexes? J. Mol. Model. 2016, 22, 284.

${ }^{44}$ Daniel, C.; Gourlaouen, C. Chemical Bonding Alteration Upon Electronic Excitation in Transition Metal Complexes. Cood. Chem. Rev. 2017, 344, 131-149.

${ }^{45}$ Ciofini, I.; Daul, C. A.; Adamo, C. Phototriggered Linkage Isomerization in RutheniumDimethylsulfoxyde Complexes: Insights from Theory . J. Phys. Chem. A 2003, 107, 11182-11190.

${ }^{46}$ Göttle, A. J.; Dixon, I. M.; Alary, F.; Heully, J.-L.; Boggio-Pasqua, M. Adiabatic Versus Nonadiabatic Photoisomerization in Photochromic Ruthenium Sulfoxide Complexes: A Mechanistic Picture from Density Functional Theory Calculations. J. Am. Chem. Soc. 2011, 133, 9172-9174.

${ }^{47}$ Göttle, A. J.; Alary, F.; Dixon, I. M.; Heully, J.-L.; Boggio-Pasqua, M. Unravelling the S $\rightarrow \mathrm{O}$ Linkage Photoisomerization Mechanisms in cis- and trans- $\left[\mathrm{Ru}(\mathrm{bpy})_{2}(\mathrm{DMSO})_{2}\right]^{2+}$ Using Density Functional Theory. Inorg. Chem. 2014, 53, 6752-6760.

${ }_{48}^{4}$ Li, H.; Zhang, L.; Wang, Y.; Fan, X. Theoretical Studies on the Photoisomerization Mechanism of Osmium(II) Sulfoxide Complexes. RSC Adv. 2015, 5, 58580-58586. 
${ }^{49}$ Li, H.; Zhang, L.; Zheng, I.; Li, X.; Fan, X.; Zhao, Y. Photoisomerization Mechanism of Ruthenium Sulfoxide Complexes: Role of the Metal-Centered Excited State in the Bond Rupture and Bond Construction Processes. Chem. Eur. J. 2016, 22, 14285-14292.

so Sanz García, J.; Alary, F.; Boggio-Pasqua, M.; Dixon, I. M.; Malfant, I.; Heully, J.-L. Establishing the Two-Photon Linkage Isomerization Mechanism in the Nitrosyl Complex trans$\left[\mathrm{RuCl}(\mathrm{NO})(\mathrm{py})_{4}\right]^{2+}$ by DFT and TDDFT. Inorg. Chem. 2015, 54, 8310-8318.

${ }^{51}$ Demas, J. N.; Crosby, G. A. Quantum Efficiencies on Transition Metal Complexes. II. Charge-Transfer Luminescence. J. Am. Chem. Soc. 1971, 93, 2841-2847.

${ }^{52}$ Demas, J. N.; Taylor, D. G. "Intersystem Crossing” Yields in Ruthenium(II) and Osmium(II) Photosensitizers. Inorg. Chem. 1979, 18, 3177-3179.

${ }_{53}$ Juris, A.; Balzani, V.; Barigelletti, F.; Campagna, S.; Belser, P.; Von Zelewsky, A. Ru(II) Polypyridine Complexes: Photophysics, Photochemistry, Electrochemistry, and Chemiluminescence. Coord. Chem. Rev. 1988, 84, 85-277.

${ }^{54}$ Damrauer, N. H.; Cerullo, G.; Yeh, A.; Boussie, T. R.; Shank, C. V.; McCusker, J. K. Femtosecond Dynamics of Excited-State Evolution in $\left[\mathrm{Ru}(\mathrm{bpy})_{3}\right]^{2+}$. Science 1997, 275, 54-57.

${ }_{5 s}$ Yeh, A. T.; Shank, C. V.; McCusker, J. K. Ultrafast Electron Localization Dynamics Following Photo-Induced Charge Transfer. Science 2000, 289, 935-938.

${ }^{56}$ Campagna, S.; Puntoriero, F.; Nastasi, F.; Bergamini, G.; Balzani, V. Photochemistry and Photophysics of Coordination Compounds: Ruthenium. Top. Curr. Chem. 2007, 280, 117-214. 
${ }^{57}$ Daul, C.; Baerends, E. J.; Vernooijs, P. A Density Functional Study of the MLCT States of $\left[\mathrm{Ru}(\mathrm{bpy})_{3}\right]^{2+}$ in $D_{3}$ Symmetry. Inorg. Chem. 1994, 33, 3538-3543.

${ }_{s 8}$ Heully, J.-L.; Alary, F.; Boggio-Pasqua, M. Spin-Orbit Effects on the Photophysical Properties of $\mathrm{Ru}(\mathrm{bpy})_{3^{2+}}$. J. Chem. Phys. 2009, 131, 184308.

${ }^{59}$ Daniel, C. Absorption Spectroscopy, Emissive Properties, and Ultrafast Intersystem Crossing Processes in Transition Metal Complexes: TD-DFT and Spin-Orbit Coupling. In DensityFunctional Methods for Excited States; Ferré, N.; Filatov, M.; Huix-Rotllant, M., Eds.; Springer; Top. Curr. Chem. 2016, 368, 377-413.

${ }^{60}$ Freitag, L.; González, L. Theoretical Spectroscopy and Photodynamics of a Ruthenium Nitrosyl Complex .Inorg. Chem. 2014, 53, 6415-6426.

${ }^{6}$ Freitag, L.; Knecht, S.; Keller, S. F.; Delcey, M. G.; Aquilante, F.; Pedersen, T. B.; Lindh, R.; Reiher, M.; González, L. Orbital entanglement and CASSCF analysis of the Ru-NO bond in a Ruthenium nitrosyl complex. Phys. Chem. Chem. Phys. 2015, 17, 14383-14392.

${ }^{62}$ Atkins, A. J.; Talotta, F.; Freitag, L.; Boggio-Pasqua, M.; González, L. Assessing excited state energy gaps with time-dependent density functional theory on $\mathrm{Ru}(\mathrm{II})$ complexes. J. Chem. Theory Comput. 2017, 13, 4123-4145.

${ }_{63}^{63}$ Finley, J.; Malmqvist, P.-Å.; Roos, B. O.; Serrano-Andrés, L. The multi-state CASPT2 method. Chem. Phys. Lett. 1998, 288, 299-306. 
${ }^{64}$ Ghigo, G.; Roos, B. O.; Malmqvist, P.- $\AA$. A modified definition of the zeroth-order Hamiltonian in multiconfigurational perturbation theory (CASPT2). Chem. Phys. Lett. 2004, $396,142-149$.

${ }^{65}$ Zobel, J. P.; Nogueira, J. J.; González, L. The IPEA dilemma in CASPT2. Chem. Sci. 2017, 8, 1482-1499.

${ }^{6}$ Aquilante, F.; Autschbach, J.; Carlson, R. K.; Chibotaru, L. F.; Delcey, M. G.; De Vico, L.; Galván, I. F.; Ferré, N.; Frutos, L. M.; Gagliardi, L.; Garavelli, M.; Giussani, A.; Hoyer, C. E.; Manni, G. L.; Lischka, H.; Ma, D.; Malmqvist, P. Å.; Müller, T.; Nenov, A.; Olivucci, M.; Pedersen, T. B.; Peng, D.; Plasser, F.; Pritchard, B.; Reiher, M.; Rivalta, I.; Schapiro, I.; SegarraMartí, J.; Stenrup, M.; Truhlar, D. G.; Ungur, L.; Valentini, A.; Vancoillie, S.; Veryazov, V.; Vysotskiy, V. P.; Weingart, O.; Zapata, F.; Lindh, R. MOLCAS 8: New Capabilities for Multiconfigurational Quantum Chemical Calculations across the Periodic Table. J. Comput. Chem. 2016, 37, 506-541.

${ }^{67}$ Angeli, C.; Cimiraglia, R.; Evangelisti, S.; Leininger, T.; Malrieu, J.-P. Introduction of $n$ electron valence states for multireference perturbation theory. J. Chem. Phys. 2001, 114, 10252.

${ }_{68}$ Weigend, F.; Ahlrichs, R. Balanced basis sets of split valence, triple zeta valence and quadruple zeta valence quality for $\mathrm{H}$ to $\mathrm{Rn}$ : Design and assessment of accuracy. Phys. Chem. Chem. Phys. 2005, 7, 3297-3305 .

${ }^{69}$ Andrae, D.; Häußermann, U.; Dolg, M.; Stoll, H.; Preuß, H. Energy-adjusted ab initio pseudopotentials for the second and third row transition elements. Theor. Chim. Acta 1990, 77, 123-141 . 
${ }^{70}$ (a) Riplinger, C.; Sandhoefer, B.; Hansen, A.; Neese, F. Natural triple excitations in local coupled cluster calculations with pair natural orbitals. J. Chem. Phys. 2013, 139, 134101. (b) Saitow, M.; Becker, U.; Riplinger, C.; Valeev, E. F.; Neese, F. A new near-linear scaling, efficient and accurate, open-shell domain-based local pair natural orbital coupled cluster singles and doubles theory. J. Chem. Phys. 2017, 146, 164105.

${ }^{7}$ Neese, F. The ORCA program system. WIREs Comput. Mol. Sci. 2012, 2, 73-78 .

${ }^{72}$ Malmqvist, P.-Å; Roos, B. O.; Schimmelpfennig, B. The restricted active space (RAS) state interaction approach with spin-orbit coupling. Chem. Phys. Lett. 2002, 357, 230-240.

${ }_{73}$ Wang, J.; Manivasagam, S.; Wilson, A. K. Multireference Character for 4d Transition MetalContaining Molecules. J. Chem. Theory Comput. 2015, 11, 5865-5872.

${ }^{74}$ Coe, B. J.; Meyer, T. J.; White, P. S. Synthetic and Structural Studies on trans-Tetrapyridine Complexes of Ruthenium(II). Inorg. Chem. 1995, 34, 593-602.

${ }^{75}$ Fumanal, M.; Daniel, C. Description of Excited States in $\left[\operatorname{Re}(\text { Imidazole })(C O)_{3}(P h e n)\right]^{+}$ Including Solvent and Spin-Orbit Coupling Effects: Density Functional Theory Versus Multiconfigurational Wavefunction Approach. J. Comp. Chem. 2016, 37, 2454-2466.

${ }^{76}$ Eng, J.; Gourlaouen, C.; Gindensperger, E.; Daniel, C. Spin-Vibronic Quantum Dynamics for Ultrafast Excited-State Processes. Acc. Chem. Res. 2015, 48, 809-817.

${ }^{7}$ Etinski, M.; Tatchen, J.; Marian, C. M.; Time-Dependent Approaches for the Calculation of Intersystem Crossing Rates. J. Chem. Phys. 2011, 134, 154105. 
${ }^{78}$ Etinski, M.; Rai-Constapel, V.; Marian, C. M.; Time-Dependent Approach to Spin-Vibronic Coupling: Implementation and Assessment. J. Chem. Phys. 2014, 140, 114104.

${ }_{79}$ Granovsky, A. A. Extended Multi-Configuration Quasi-Degenerate Perturbation Theory: The New Approach to Multi-State Multi-Reference Perturbation Theory. J. Chem. Phys. 2011, 134, 214113.

${ }^{80}$ El-Sayed, M. A. Spin-Orbit Coupling and the Radiationless Processes in Nitrogen Heterocyclics. J. Chem. Phys. 1963, 38, 2834-2838.

${ }^{81}$ McCusker, J. K. Femtosecond Absorption Spectroscopy of Transition Metal Charge-Transfer Complexes. Acc. Chem. Res. 2003, 36, 876-887.

${ }^{82}$ Forster, L. S. Intersystem Crossing in Transition Metal Complexes. Coord. Chem. Rev. 2006, 250, 2023-2033.

${ }^{83}$ Chergui, M. Ultrafast Photophysics of Transition Metal Complexes. Acc. Chem. Res. 2015, 48, 801-808.

${ }^{84}$ Vlček, Jr. A.; Záliš, S. Modeling of Charge-Transfer Transitions and Excited States in d Transition Metal Complexes by DFT Techniques. Coord. Chem. Rev. 2007, 251, 258-287.

${ }^{85}$ Lee, T. J.; Rice, J. E.; Scuseria, G. E.; Schaefer III, H. F. Theoretical Investigations of Molecules Composed Only of Fluorine, Oxygen and Nitrogen: Determination of the Equilibrium Structures of FOOF, (NO) 2 and FNNF and the Transition State Structure for FNNF cis-trans Isomerization. Theor. Chim. Acta 1989, 75, 81-98. 
${ }^{86}$ Lee, T. J.; Taylor, P. R. A Diagnostic for Determining the Quality of Single-Reference Electron Correlation Methods. Int. J. Quantum Chem. 1989, S23, 199-207.

GRAPHICAL ABSTRACT.

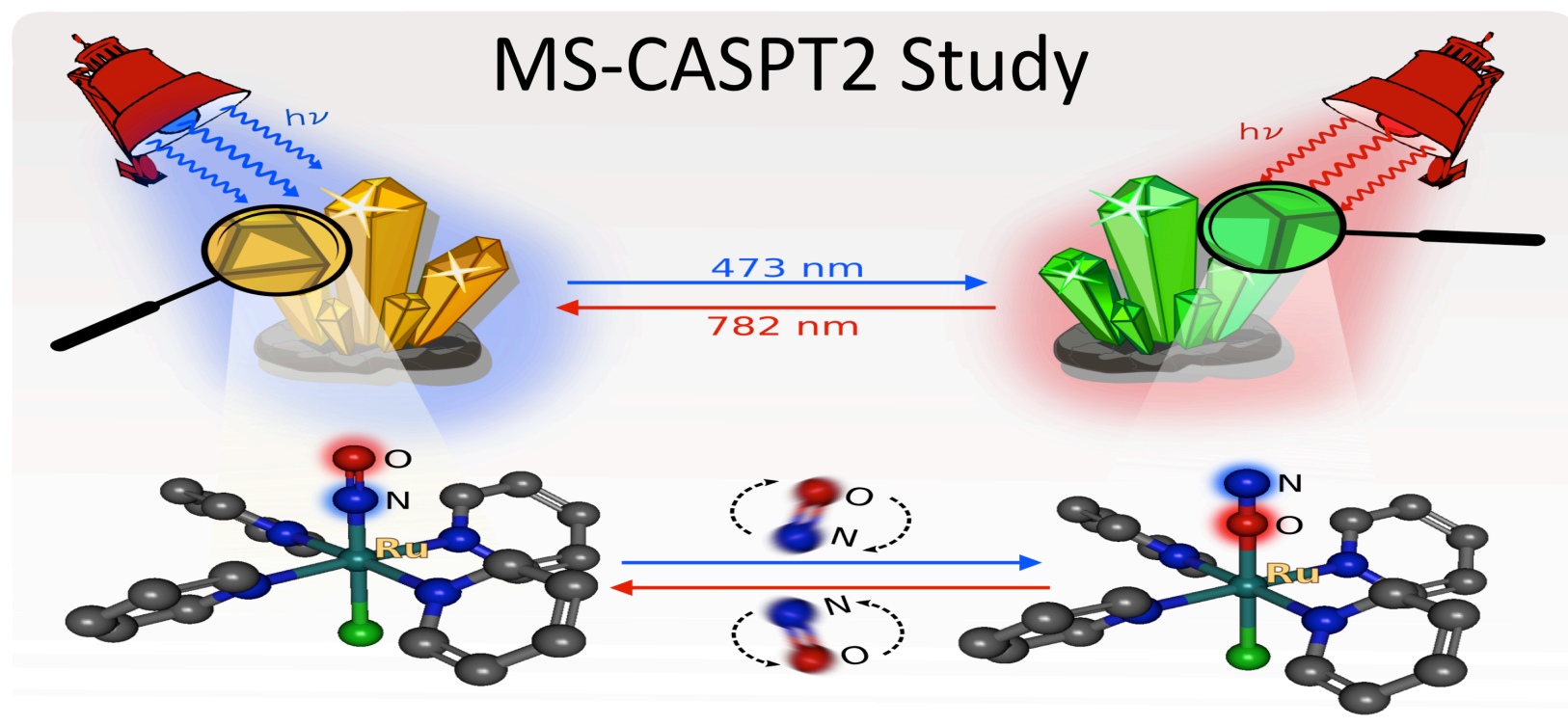


